Article

\title{
Assessment of Atmospheric Correction Methods for Sentinel-2 MSI Images Applied to Amazon Floodplain Lakes
}

\author{
Vitor Souza Martins ${ }^{1, *}$, Claudio Clemente Faria Barbosa ${ }^{1}$, Lino Augusto Sander de Carvalho ${ }^{1}$, \\ Daniel Schaffer Ferreira Jorge ${ }^{1}$, Felipe de Lucia Lobo ${ }^{2}$ and Evlyn Márcia Leão de Moraes Novo ${ }^{2}$ \\ 1 Image Processing Division, Brazilian Institute for Space Research, São José dos Campos 12227-010, Brazil; \\ claudio.barbosa@inpe.br (C.C.F.B.); lino@dsr.inpe.br (L.A.S.C.); danielsfj@dsr.inpe.br (D.S.F.J.) \\ 2 Remote Sensing Division, Brazilian Institute for Space Research, São José dos Campos 12227-010, Brazil; \\ felipe.lobo@inpe.br (F.L.L.); evlyn.novo@inpe.br (E.M.L.M.N.) \\ * Correspondence: vitor.martins@inpe.br or vitorstmartins@gmail.com; Tel.: +55-12-3208-6809
}

Academic Editors: Yunlin Zhang, Claudia Giardino, Linhai Li, Xiaofeng Li and Prasad S. Thenkabail Received: 16 January 2017; Accepted: 24 March 2017; Published: 29 March 2017

\begin{abstract}
Satellite data provide the only viable means for extensive monitoring of remote and large freshwater systems, such as the Amazon floodplain lakes. However, an accurate atmospheric correction is required to retrieve water constituents based on surface water reflectance $\left(R_{W}\right)$. In this paper, we assessed three atmospheric correction methods (Second Simulation of a Satellite Signal in the Solar Spectrum (6SV), ACOLITE and Sen2Cor) applied to an image acquired by the MultiSpectral Instrument (MSI) on-board of the European Space Agency's Sentinel-2A platform using concurrent in-situ measurements over four Amazon floodplain lakes in Brazil. In addition, we evaluated the correction of forest adjacency effects based on the linear spectral unmixing model, and performed a temporal evaluation of atmospheric constituents from Multi-Angle Implementation of Atmospheric Correction (MAIAC) products. The validation of MAIAC aerosol optical depth (AOD) indicated satisfactory retrievals over the Amazon region, with a correlation coefficient $(\mathrm{R})$ of $\sim 0.7$ and 0.85 for Terra and Aqua products, respectively. The seasonal distribution of the cloud cover and AOD revealed a contrast between the first and second half of the year in the study area. Furthermore, simulation of top-of-atmosphere (TOA) reflectance showed a critical contribution of atmospheric effects $(>50 \%)$ to all spectral bands, especially the deep blue $(92 \%-96 \%)$ and blue $(84 \%-92 \%)$ bands. The atmospheric correction results of the visible bands illustrate the limitation of the methods over dark lakes $\left(R_{W}<1 \%\right)$, and better match of the $R_{W}$ shape compared with in-situ measurements over turbid lakes, although the accuracy varied depending on the spectral bands and methods. Particularly above $705 \mathrm{~nm}, \mathrm{R}_{\mathrm{W}}$ was highly affected by Amazon forest adjacency, and the proposed adjacency effect correction minimized the spectral distortions in $R_{W}$ (RMSE < 0.006). Finally, an extensive validation of the methods is required for distinct inland water types and atmospheric conditions.
\end{abstract}

Keywords: Amazon inland water; MAIAC aerosol product; adjacency correction; TOA simulation; MODIS atmospheric product; atmospheric correction

\section{Introduction}

Inland waters are an essential resource for terrestrial life and ecosystem services [1,2]. The Amazon freshwater is an ecosystem bearing one of the highest biodiversities in the world [3]. Amazonian aquatic systems depend on satellite image applications to investigate bio-optical parameters due to the extent and limitations of in-situ measurements [4-7]. Thus, remote sensing images have long been recognized as a potential data source for the continuous modelling and monitoring of the water quality [8]. 
The new generation of orbital optical sensors, such as Sentinel-2 and Landsat-8, presents a scientific opportunity for inland water research [9]. The Multispectral Imager (MSI) on-board Sentinel-2A delivers images with high spatial (10-30 m), temporal (10 days) and radiometric (12 bits) resolutions [10]. These configurations offer capabilities for the mapping of small and irregular open-water systems, higher sensitivity to bio-optical variables and higher temporal observations enabling the monitoring of changes in the water composition over time. In addition, MSI has been designed with eight spectral bands in the visible and near-infrared (NIR) wavelengths that are feasible for water research of the main optically active components (OACs): chlorophyll-a (Chl-a), total suspended solids (TSS) and coloured dissolved organic matter (CDOM) [11]. In a preliminary assessment of the MSI application, Toming et al. [12] reported reasonable retrievals of Chl-a and CDOM concentrations based on a historical dataset from Estonian lakes. Thus, Sentinel-2 MSI data represent a new perspective for inland and coastal waters [13-15].

Atmospheric correction is a prerequisite to quantify biogeochemical properties based on surface reflectance, once it removes attenuation effects caused by active atmospheric constituents, such as molecular and aerosol scattering and absorption by water vapour, ozone, oxygen and carbon dioxide [16]. In fact, due to the low reflectance, the accurate removal of atmospheric effects is paramount for water surfaces [17]. The surface reflectance quality is highly dependent on the atmospheric correction method, atmospheric-surface characteristics, and sensor design [18].

Several atmospheric correction algorithms are available for multispectral sensors which can be divided in two main categories [19]: (i) image-based approach; and (ii) atmospheric radiative transfer codes (RTCs). In the first category, the atmospheric effects are derived from the image itself and then removed from the TOA signal. For instance, ESA provides a Sentinel toolbox that includes a Sen2Cor processor to generate MSI land products (Level 2A). This processor is a semi-empirical algorithm that integrates image-based retrievals with Look-Up tables (LUTs) from the LibRadtran model to remove atmospheric effects from MSI images [20]. In parallel, Vanhellemont and Ruddick [21] developed an image-based processor, named ACOLITE, for the atmospheric correction of Operational Land Imager (OLI) and MSI images applied to marine and inland water studies. The ACOLITE computes aerosol scattering using Rayleigh-corrected reflectance from NIR bands for clear water and SWIR bands for moderate and turbid water; the water contribution measured in these bands can be negligible [22]. Overall, both ACOLITE and Sen2Cor are image-based approaches available for MSI images and present an advantage in regions without external atmospheric information. In the second category, RTCs compute scattering and absorption of light through the atmosphere to remove them from the signal measured by satellite sensors. The $6 \mathrm{~S}$ vector version (Second Simulation of a Satellite Signal in the Solar Spectrum) is a well-established RTC that accounts for a wide variety of atmospheric conditions and sensor characteristics [23]. However, the main implication of using RTC is the prior knowledge about atmospheric parameters (e.g., aerosol optical depth (AOD), water vapour and ozone) coinciding with the satellite overpass. In general, this information is available from climatological models [24], sun photometer measurements [25] or satellite atmospheric products [26]. Among the alternatives, recent Moderate Resolution Imaging Spectroradiometer (MODIS) algorithm, named Multi-angle implementation of atmospheric correction (MAIAC), provides a suite of atmospheric products (AOD, cloud mask and water vapour) at fine $1 \mathrm{~km}$ resolution [27], which is promising for enhanced quality information in regions with high cloud cover areas such as the Amazon region [28].

In addition to atmospheric correction issues, the contribution of adjacency effects also demands correction [29,30]. In the Amazon context, the presence of dense forest around water bodies contributes to modify the water spectrum measured by orbital sensors. Therefore, remote sensing of the Amazonian water system faces several challenges, such as: (i) dynamic system with optically complex water; (ii) logistical difficulties in collecting water samples and validation data; (iii) seasonal variability of aerosol loading from biomass burning plumes (iv); high cloud cover and cloud cirrus; and (v) forest adjacency effects. In view of these challenges, the critical assessment of atmospheric correction methods applied to new Sentinel 2 MSI image is required, which is still missing for Amazon lakes. 
Therefore, our objective is to present an inter-comparison of three atmospheric correction algorithms (6SV based on MAIAC atmospheric product, ACOLITE and Sen2Cor) applied to new a Sentinel-2 MSI image in the case of Amazon floodplain lakes. Regarding atmospheric correction, we conducted a supplementary analysis to understand atmospheric components in the study area, and then, simulated the contribution of atmospheric and surface reflectance to MSI TOA bands. Finally, we developed an adjacency correction based on the Linear Spectral Unmixing (LSU) model for water surfaces, due to the strong forest adjacent effects on the water spectrum. All comparisons were conducted over four Amazon floodplain lakes using in-situ radiometric measurements concurrent to the MSI image overpass.

\section{Materials}

\subsection{Site Description and Field Data}

Our study area consists of four Amazon floodplain lakes located in the Mamirauá Sustainable Development Reserve (MSDR), close to the confluence of the Solimões and Japurá Rivers ( 25 km) (Figure 1). The MSDR is a complex floodplain ecosystem that remains entirely flooded for 3-6 months due to seasonal water level variation. The annual average amplitude of the water level reaches $\sim 10.6 \mathrm{~m}$ [31]. In the MSDR lakes, OACs concentrations change seasonally driven by exchange flow (in- and out-flowing) with large fluvial systems, such as the Japurá and Solimões rivers [32]. Few studies reported the bio-optical properties for this Amazon region (e.g., Affonso et al. [33]), since most efforts concentrated on multidisciplinary reports about the ecological management, fish communities and ecosystem disturbance [34,35]. In general, MSDR integrates a sustainable use of natural resources and preservation practices, where local communities are committed to rational resource exploitation, and biodiversity protection in the reserve [36]. Thus, the MSDR represents an ecological and sustainable model for human-environment relations, and becomes an attractive region for further studies of bio-optical patterns and natural conservation using remote sensing data.

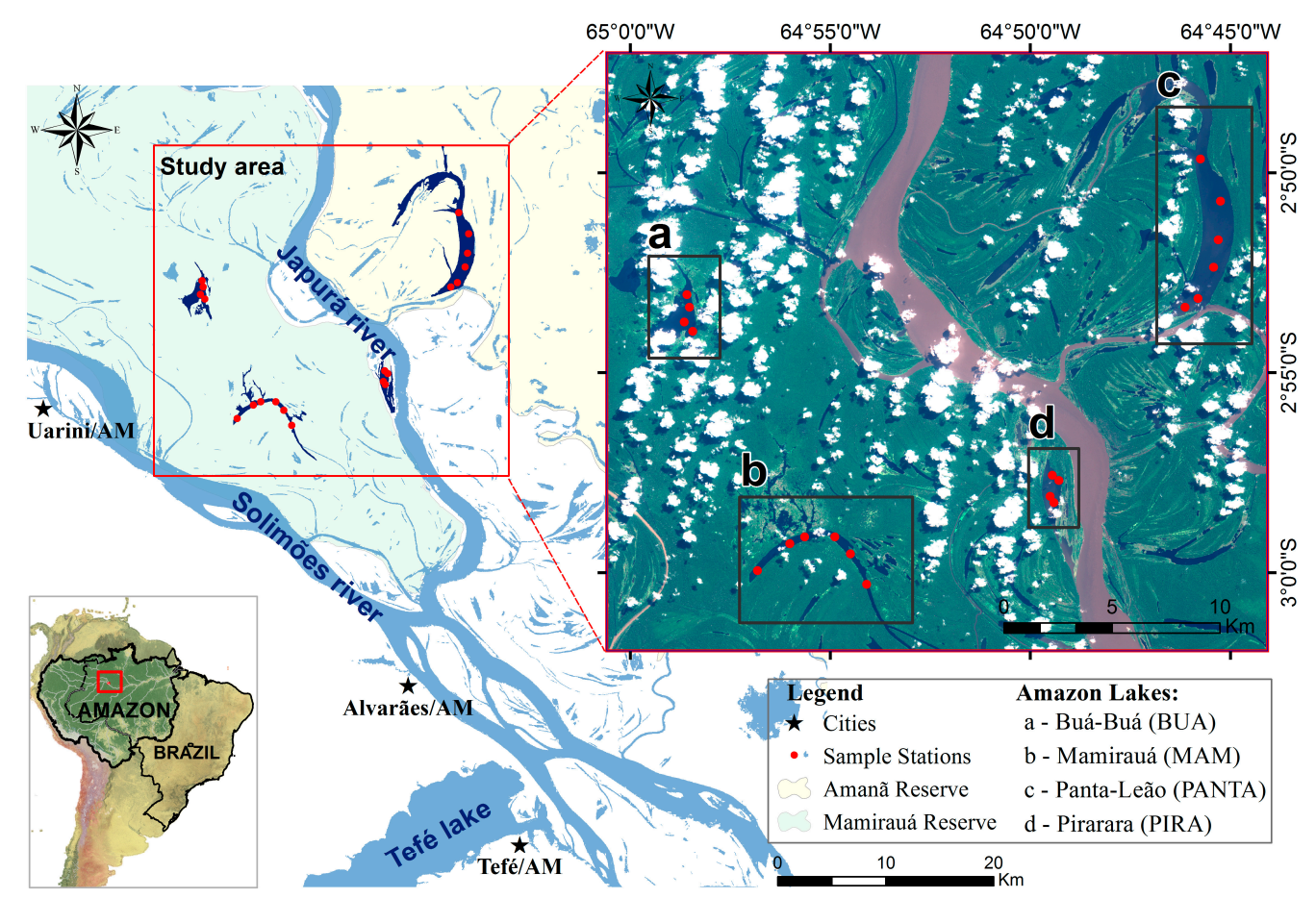

Figure 1. Overview of study area and sample stations over four Amazon floodplain lakes: (a) Buá-Buá; (b) Mamirauá; (c) Panta-leão; and (d) Pirarara. 
Radiometric measurements were carried out at twenty sample stations during 12-19 August 2016 (Figure 1). Inter-calibrated Trios-RAMSES radiometers were used to measure the above water upwelling radiance $\left(\mathrm{L}_{\mathrm{w}}^{+0}\left[\mathrm{~W}[\mathrm{watt}] \cdot \mathrm{m}^{-2} \cdot \mathrm{sr}^{-1} \cdot \mathrm{nm}^{-1}\right]\right)$, sky radiance $\left(\mathrm{L}_{\mathrm{sky}}^{+0}\left[\mathrm{wW}[\mathrm{watt}] \cdot \mathrm{m}^{-2} \cdot \mathrm{sr}^{-1} \cdot \mathrm{nm}^{-1}\right]\right)$ and above surface downwelling irradiance $\left(\mathrm{E}_{\mathrm{d}}^{+0}\left[\mathrm{~W}[\mathrm{watt}] \cdot \mathrm{m}^{-2} \cdot \mathrm{sr}^{-1} \cdot \mathrm{nm}^{-1}\right]\right)$, within $350-900$ wavelengths. The sensors view followed the framed description of Mobley [37], whereas $\mathrm{L}_{\mathrm{w}}^{+0}$ has a relative azimuth angle $\left(\phi_{\mathrm{v}}\right)$ within $90^{\circ}-135^{\circ}$ from the sun and a zenith angle $\left(\theta_{\mathrm{v}}\right)$ of $45^{\circ}$ from the nadir, and $\mathrm{L}_{\text {sky }}$ has a zenith angle $\left(\theta_{\mathrm{v}}^{\prime}\right)$ of $\theta_{\mathrm{v}}+90^{\circ}$ from nadir. All radiometers operate simultaneously, and measurements were performed within a 3-h interval (10:00 a.m.-13:00 p.m.) to avoid potential impact of specular reflection (glint) at low sun angles. In the pre-processing, all spectroradiometric measurements were interpolated for $1 \mathrm{~nm}$ interval (originally $3.3 \mathrm{~nm}$ ) and were normalized by sky reference. The remote sensing reflectance $\left(R_{\mathrm{rs}}\right)$ was calculated at each sampling station according to Mobley [37]:

$$
R_{\mathrm{rs}}\left(\theta_{\mathrm{v}}, \phi_{\mathrm{v}}, \lambda\right)=\left(\frac{\mathrm{L}_{\mathrm{w}}^{+0}\left(\theta_{\mathrm{v}}, \phi_{\mathrm{v}}, \lambda\right)-\mathrm{r}_{\mathrm{sky}}\left(\theta_{\mathrm{v}}^{\prime}, \phi_{\mathrm{v}}, \theta_{0}, \mathrm{~W}\right) \times \mathrm{L}_{\mathrm{sky}}^{+0}\left(\theta_{\mathrm{v}}^{\prime}, \phi_{\mathrm{v}}, \lambda\right)}{\mathrm{E}_{\mathrm{d}}^{+0}(\lambda)}\right)
$$

Afterwards, water reflectance $\left(\mathrm{R}_{\mathrm{w}^{*}}\right)$ is calculated as:

$$
\mathrm{R}_{\mathrm{w}^{*}}=\pi \cdot \mathrm{R}_{\mathrm{rs}}
$$

where, $r_{\text {sky }}$ is the air-water interface reflection coefficient that minimizes skylight reflection effects, and can be obtained in Mobley [38] as a function of a given view zenith and azimuth angles $\left(\theta_{\mathrm{v}} ; \phi_{\mathrm{v}}\right)$, sun zenith angle $\left(\theta_{0}\right)$ and wind speed $W(\mathrm{~m} / \mathrm{s})$. In-situ $\mathrm{R}_{\mathrm{W}^{*}}$ spectra were weighted by spectral response functions $\operatorname{SRF}(\lambda)$ of MSI bands, thus deriving a multi-spectral data comparable to atmospherically corrected MSI-reflectance from image.

$$
\mathrm{R}_{\mathrm{w}, \text { situ }}\left(\lambda_{\mathrm{i}}\right)=\frac{\int_{\mathrm{k}} \mathrm{R}_{\mathrm{w}^{*}}(\lambda) \times \operatorname{SRF}(\lambda) \mathrm{d} \lambda}{\int_{\mathrm{k}} \operatorname{SRF}(\lambda) \mathrm{d} \lambda}
$$

where $R_{w, s i t u}\left(\lambda_{i}\right)$ is the MSI reflectance simulated from in-situ reflectance, $k$ is bandwidth (nm), $\lambda_{i}$ is the central wavelength of spectral band, and $i$ is the number of MSI spectral band.

Figure 2 shows the magnitude contrast of the mean and standard deviation of $\mathrm{R}_{\mathrm{w}^{*}}$ spectra among lakes. Although all lakes present a typical low spectral reflectance $(<2 \%)$, Panta-Leão and Pirarara lakes have 2.5 times higher spectral $\mathrm{R}_{\mathrm{w}^{*}}$ than those of Buá-Buá and Mamirauá lakes. Indeed, boundary conditions influence bio-optical differences between these lakes, and consequently, contribute to the shape and magnitude contrast of water reflectances. In this context, Mamirauá and Buá-Buá lakes, hereafter called dark lakes, receive a great amount of organic matter content due to the interaction with dense forest reaching heights of up to $40 \mathrm{~m}$ (Wittmann et al. 2004). On the other hand, Panta-Leão and Pirarara lakes, hereafter called bright lakes, are directly connected to the Japurá River and exchange a huge volume of water with high sediment loading. We therefore established all discussions based on these two distinct optical conditions; results are referred to as a function of dark and bright lakes. 


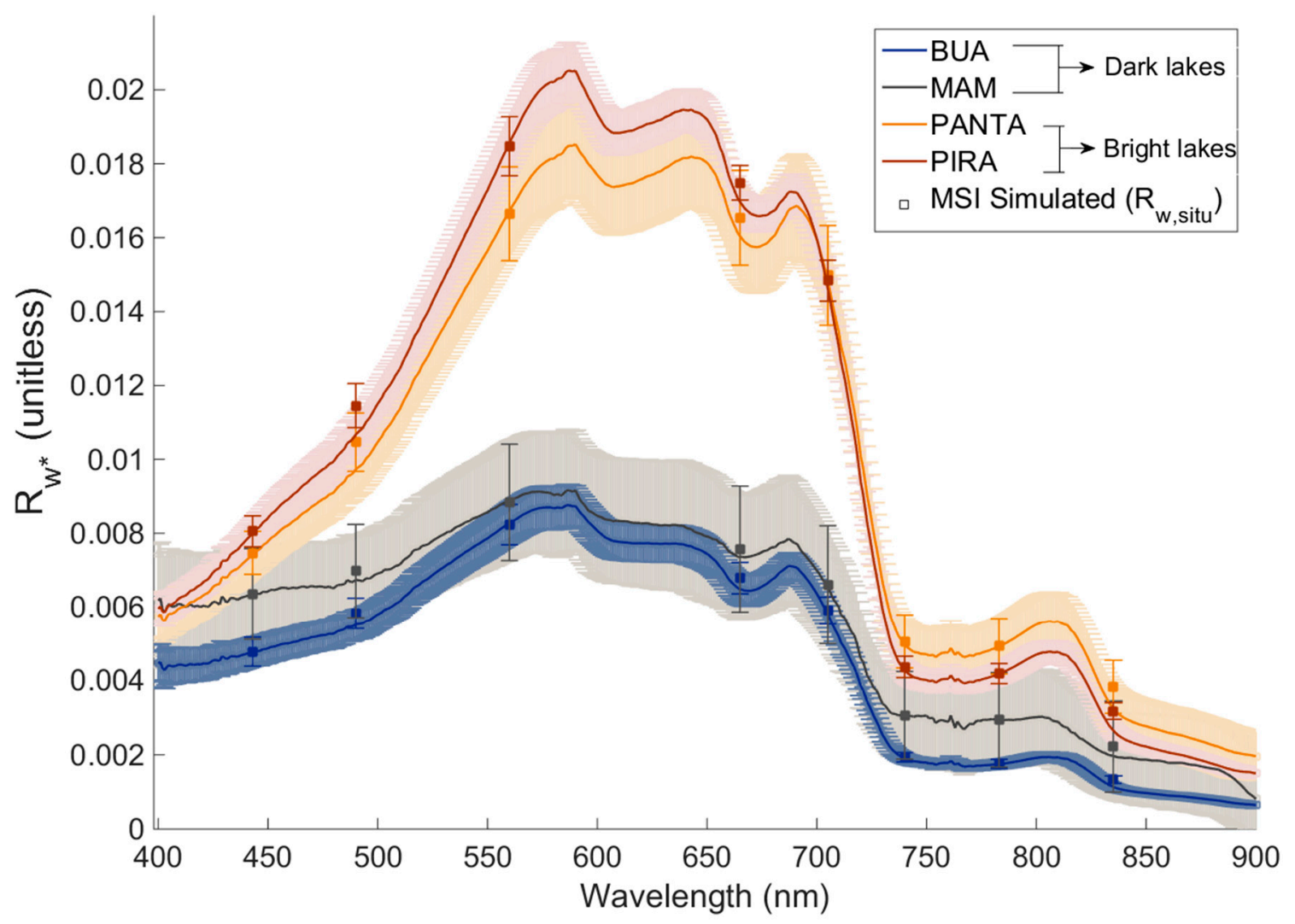

Figure 2. Average (solid line) and standard deviation (shadow-coloured) of water reflectance measured on four Amazon lakes: Buá-Buá (BUA), Mamirauá (MAM), Panta-Leão (PANTA) and Pirarara (PIRA). The square markers and error bars are Multi-Spectral Instrument (MSI) reflectance simulated $\left(\mathrm{R}_{\mathrm{W}, \text { situ }}\right)$ and their standard deviation, respectively.

\subsection{MSI/Sentinel-2 Data}

Multi-Spectral Instrument (MSI) on board Sentinel-2 satellite is an optical pushbroom sensor that acquires multi-spectral data for Earth science [39]. The Sentinel-2 mission includes two identical satellites operating in sun-synchronous orbit, with operational Sentinel-2A satellite launched in June 2015, and Sentinel-2B planned for 2017. These twin polar-orbiting satellites allow a high 5-day revisit time of the equator (after the launch of Sentinel-2B), because they are phased at $180^{\circ}$ to each other. The high-resolution MSI data include 13 spectral bands from Visible and Near-Infrared (VNIR) to Short Wave InfraRed (SWIR) region, fine spatial resolution $(10,20$ and $60 \mathrm{~m})$, and 12 bit quantization (Table 1) [10]. Additionally, the MSI sensor enhances spectral capabilities that include useful bands for land and atmospheric observations, such as the deep blue band $(443 \mathrm{~nm})$ for coastal and aerosol retrievals, cirrus detection at $1375 \mathrm{~nm}$ and three red-edge bands for vegetation and water studies [40]. Therefore, all those high optical properties configure an attractive sensor for inland water studies, in particular, over high cloud cover regions (e.g., Amazon Basin) due to the high temporal resolution. The standard MSI scene is delivered as Level-1C (L1C) product with radiometric and geometric correction in UTM/WGS84 projection [41].

Simultaneously with the field observations, a cloud-free MSI image was acquired on 12 August 2016 at 14:37 UTC. Our study area is located within MSI granule 20MKB, which was downloaded from the Copernicus Scientific Data Hub website. As a first procedure, all MSI bands were resampled to a $10 \mathrm{~m}$ pixel size and the TOA reflectance was divided by a rescaling coefficient of 10,000 . The granule has $\sim 2 \%$ of cloud cover on granule, and particular cloud-free conditions over our twenty sample stations. Thus, in-situ measurements can be used to compare the MSI surface reflectance derived from atmospheric correction methods. 
The time gap between in-situ measurements and the satellite overpass affects the reflectance comparison. Several studies discussed the time gap with respect to reservoir and lake research and the results pointed out that a comparison using measurements with \pm 3 or up to \pm 8 days is reasonable when the water and environmental conditions do not present rapid changes [42-45]. In our case, logistical and distances imposed difficulties to access all floodplain lakes concurrently with the satellite overpass. Thus, we started the radiometric measurements on 12 August concurrently with Sentinel-2 overpass, and were sampling new stations every day until all sample stations were completed by 19 August. The number of stations was limited to 2-3 per day to guarantee feasible solar conditions. Note that more than $50 \%$ of all sample station data were collected within three days from the satellite overpass, reducing the temporal influence on the radiometric dataset. Although the lakes exchange water with the Japurá River, variation of the water level during this season is a gradual process that relies on channel connections and hydrological periods. Additionally, all lakes presented a depth $(>5 \mathrm{~m})$ and low wind speed $(\sim 1 \mathrm{~m} / \mathrm{s})$ that minimize resuspension and circulation of sediment from the bottom. Therefore, the time gap between MSI image (12 August) and in-situ measurements (12-19 August) was in principle not considered to be an issue for the comparisons.

Table 1. Spectral bands of MSI sensor on-board Sentinel-2 satellite.

\begin{tabular}{|c|c|c|c|c|}
\hline MSI Bands (Spatial Resolution) & Central Wavelength (nm) & Bandwidth (nm) & Lref $\left(W \cdot m^{-2} \cdot s^{-1} \cdot \mu m^{-1}\right)$ & SNR at Lref \\
\hline Band $2(10 \mathrm{~m})$ & 490 (Blue) & 65 & 128 & 154 \\
\hline Band $4(10 \mathrm{~m})$ & 665 (Red) & 30 & 108 & 142 \\
\hline Band 5 (20 m) & 705 (Red-edge) & 15 & 74.5 & 117 \\
\hline Band $6(20 \mathrm{~m})$ & 740 (Red-edge) & 15 & 68 & 89 \\
\hline Band $8 \mathrm{~A}(20 \mathrm{~m})$ & 865 (NIR) & 20 & 52.5 & 72 \\
\hline Band $9(60 \mathrm{~m})$ & 945 (NIR) & 20 & 9 & 114 \\
\hline Band $10(60 \mathrm{~m})$ & 1375 (SWIR) & 30 & 6 & 50 \\
\hline Band $11(20 \mathrm{~m})$ & 1610 (SWIR) & 90 & 4 & 100 \\
\hline Band $12(20 \mathrm{~m})$ & 2190 (SWIR) & 180 & 1.5 & 100 \\
\hline
\end{tabular}

\subsection{MAIAC Atmospheric Data}

Several MODIS algorithms were developed to provide atmospheric products, such as aerosol optical depth, column water vapour and ozone [46-48]. Continuous efforts have been made to enhance the accuracy of atmospheric retrievals from MODIS data. In addition to climate research, these atmospheric products are also used as input in the atmospheric correction of optical images [49]. In this context, the MAIAC algorithm was developed to derive a surface bidirectional reflectance distribution function (BRDF) from MODIS data and a suite of atmospheric products at a high $1 \mathrm{~km}$ resolution [27]. These atmospheric products include the cloud and cloud shadow mask, aerosol optical depth at 0.47 and $0.55 \mu \mathrm{m}$ and column water vapour $\left(\mathrm{U}_{\mathrm{H} 2 \mathrm{O}}\right.$ ) (see Lyapustin et al. [27,50] for more details). Figure 3 shows the MOD09 surface reflectance product and a comparison of three MODIS aerosol products for the same day of MSI image (12 August 2016): (Figure 3b) MAIAC AOD 1 km; (Figure 3c) MOD04 3 km Collection 6; and (Figure 3d) MOD04 $10 \mathrm{~km}$ Collection 6. There is a clear difference in the number of valid AOD retrievals between fine resolution MAIAC and MOD4 AOD products. Cloudy conditions limited the wide coverage of MOD04 retrievals at 3 and $10 \mathrm{~km}$ resolutions, while the fine-scale MAIAC retrieves AOD information for an individual set of cloud-free pixels. In our case, both Sentinel-2A and Terra satellite have an almost concurrent overpass ( 10:30 a.m.), which guarantees fair applications of MODIS atmospheric products as auxiliary information in atmospheric correction. Thus, we selected tile h01v01 of the MAIAC atmospheric product on 12 August 2016. The average of $\mathrm{AOD}_{550}$ and $\mathrm{U}_{\mathrm{H} 2 \mathrm{O}}$ within a $2 \mathrm{~km}$ buffer from each lake was used as input for the 6SV model (Table 2). In addition, columnar ozone content was obtained from MODIS global daily product (MOD08_D3-Total_Ozone_mean) on 12 August 2016. 

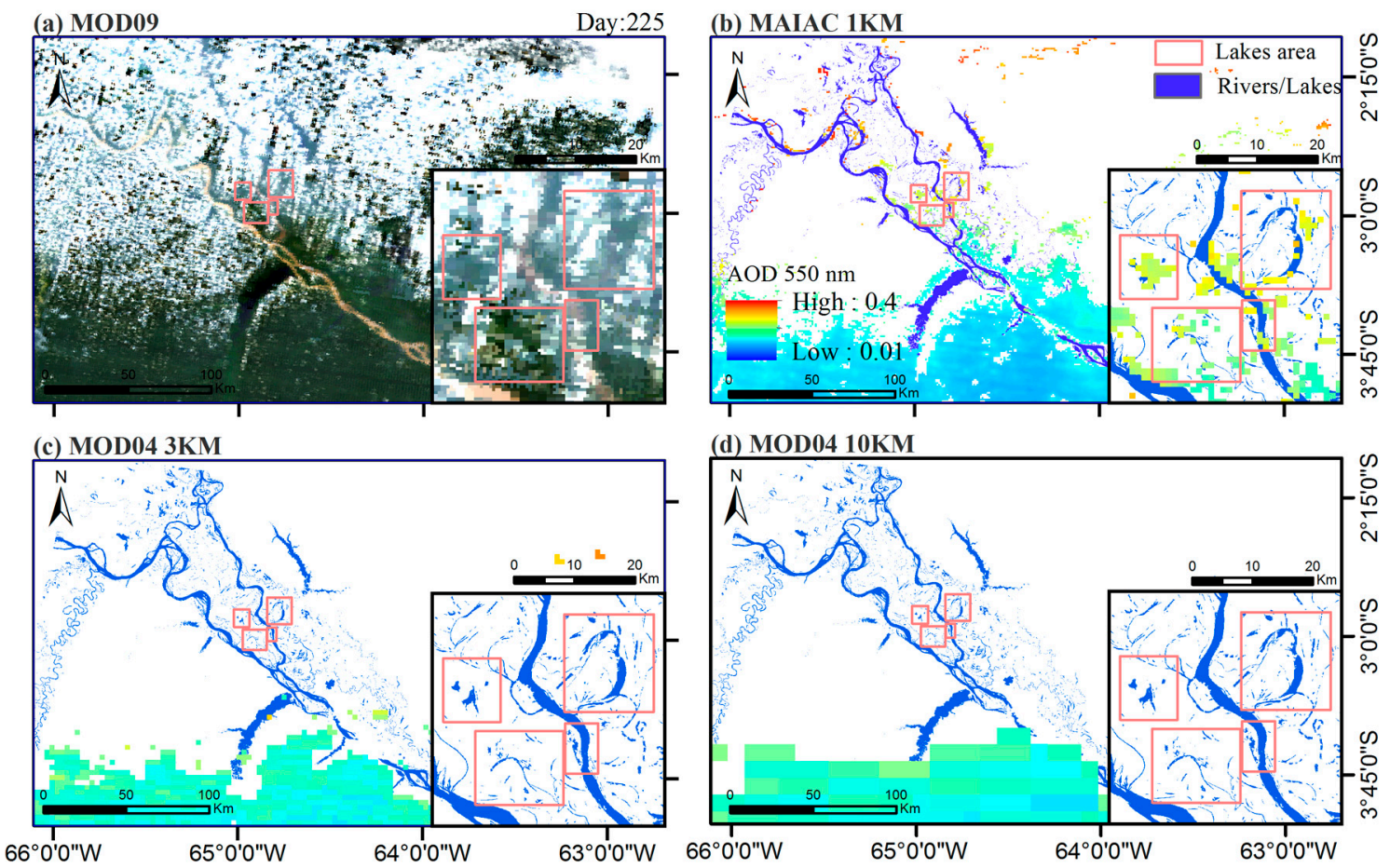

Figure 3. MODIS AOD products concurrently with MSI image on 12 August 2016: (a) MOD09 surface reflectance; (b) MAIAC AOD550 1 km; (c) MOD04 3 km Collection 6; and (d) MOD04 10 km Collection 6.

Table 2. Input parameters of 6SV model for Sentinel MSI image.

\begin{tabular}{ccccc}
\hline Parameters & BUA & MAM & PANTA & PIRA \\
\hline Solar zenith angle $\left(^{\circ}\right)$ & 30.96 & 30.96 & 30.96 & 30.96 \\
Solar azimuth angle $\left(^{\circ}\right)$ & 53.99 & 53.99 & 53.99 & 53.99 \\
\hline Aerosol Model & \multicolumn{4}{c}{ Biomass Burning } \\
\hline AOD at 550 nm ${ }^{1}$ & 0.3 & 0.26 & 0.34 & 0.3 \\
Ozone $(\mathrm{cm}-\mathrm{atm})$ & 0.346 & 0.346 & 0.346 & 0.346 \\
Water vapour $\left(\mathrm{g} / \mathrm{cm}^{2}\right)$ & 4.88 & 4.7 & 4.06 & 4.15 \\
Terrain elevation $(\mathrm{km})$ & 0.04 & 0.04 & 0.04 & 0.04 \\
\hline
\end{tabular}

${ }^{1}$ AOD adjusted by Terra bias (Section 4.1).

The assessment of MAIAC $\mathrm{AOD}_{550}$ is still missing in the Amazon region. Therefore, we performed an evaluation of this satellite AOD product by comparing it with ground measurements. In this context, AERONET program is a global sun-photometer network that provides a multi-spectral sun and sky radiance to derive aerosol optical properties, such as AOD and angstrom exponent information [25]. There are three long-term operational AERONET sites in the Amazon basin: Balbina (1993-2003), Belterra (1996-2005), and Manaus-Embrapa (2011-2016). These sites provide consolidated ground-truth data for the quality evaluation of satellite aerosol products. Therefore, we compared MAIAC AOD retrievals at $550 \mathrm{~nm}$ with AERONET observations based on procedures used by Lyapustin et al. [27]. Besides validation of AOD products, we also calculated the monthly average of AOD 550 , columnar water vapour and cloud cover frequency within the Mamirauá region (see red box in Figure 1) using the 15-year MAIAC Terra products (2000-2015). This temporal analysis provides background knowledge of the most variable atmospheric constituents in the study area. 


\section{Methods}

In this section, we present three atmospheric correction methods used for the MSI image and forest adjacency correction: (Section 3.1.) $6 \mathrm{SV}$ model based on MAIAC $A O D_{550}$ and $\mathrm{U}_{\mathrm{H} 2 \mathrm{O}}$ products; (Section 3.2.) ACOLITE algorithm; (Section 3.3) Sen2Cor algorithm; and (Section 3.4) forest adjacency correction based on the LSU model. Based on the MSI-corrected image, we calculated the average of water surface reflectance using a $3 \times 3$-pixel box centered at each sample station to perform a direct comparison with in-situ measurements.

\section{1. $6 S$ V Model + MAIAC Atmospheric Products}

The 6SV model is a robust radiative transfer code for the atmospheric correction of different satellite data for a variety of climatological conditions [23]. The atmospheric radiative transfer computes attenuation effects caused by the scattering of molecules and aerosols and gaseous absorption by water vapour $\left(\mathrm{H}_{2} \mathrm{O}\right)$, carbon dioxide $\left(\mathrm{CO}_{2}\right)$, oxygen $\left(\mathrm{O}_{2}\right)$, and ozone $\left(\mathrm{O}_{3}\right)$. Currently, the $6 \mathrm{SV}$ model is an operational model used to derive the surface reflectance product from MODIS, ETM+ and OLI images [51,52]. The comparison of 6SV with other complex RTCs, such as SHARM, DISORT and MODTRAN, showed that the vector mode is highly accurate and provides fair agreement results that agree with other RTCs [53]. Due to consistency of multiple sensors and generic features, we used the $6 \mathrm{SV}$ model (version 1.1) to evaluate the atmospheric correction of the MSI image. For a given sun-view geometry, sensor characteristics, atmospheric condition and surface reflectance $\left(\mathrm{R}_{\text {sur }}\right)$, TOA reflectance can be estimated with the following Equation (4) [23]:

$$
\begin{aligned}
& \mathrm{R}_{\mathrm{TOA}}\left(\lambda, \theta_{\mathrm{v}}, \phi_{\mathrm{v}}, \theta_{0}, \phi_{0}\right)=\left[\mathrm{R}_{\mathrm{R}+\mathrm{A}}\left(\lambda, \theta_{\mathrm{v}}, \theta_{0}, \phi_{0}\right)\right. \\
& \left.+\mathrm{t}_{\mathrm{d}}\left(\lambda, \theta_{0}\right) \mathrm{t}_{\mathrm{u}}\left(\lambda, \theta_{\mathrm{v}}\right) \frac{\mathrm{R}_{\mathrm{sur}}(\lambda)}{1-\mathrm{S}(\lambda) \mathrm{R}_{\mathrm{sur}}(\lambda)}\right] \mathrm{T}_{\mathrm{g}}\left(\lambda, \theta_{\mathrm{v}}, \theta_{0},\right)
\end{aligned}
$$

where $T_{g}$ refers to gaseous transmission of the principal absorbing constituents $\left(\mathrm{O}_{2}, \mathrm{O}_{3}, \mathrm{CO}_{2}, \mathrm{H}_{2} \mathrm{O}\right)$; $R_{R+A}$ is the molecular and aerosol scattering intrinsic reflectance; $t_{d}$ and $t_{u}$ represent the atmospheric transmittance of aerosol and molecular from sun to target and target to sensor, respectively; $\mathrm{S}$ is the atmosphere spherical albedo of the atmosphere; and $\theta_{\mathrm{v}}, \phi_{\mathrm{v}}, \theta_{0}, \phi_{0}$ are the view zenith, view azimuth, solar zenith and solar azimuth angles, respectively. Solving Equation (4) for surface reflectance and simplifying notations of angles, the atmospheric correction proceeds as following Equation (5):

$$
\mathrm{R}_{\text {sur }}=\left(\mathrm{R}_{\mathrm{TOA}} / \mathrm{T}_{\mathrm{g}}-\mathrm{R}_{\mathrm{R}+\mathrm{A}}\right) /\left[\mathrm{t}_{\mathrm{d}} \mathrm{t}_{\mathrm{u}}+\mathrm{S}\left(\mathrm{R}_{\mathrm{TOA}} / \mathrm{T}_{\mathrm{g}}-\mathrm{R}_{\mathrm{R}+\mathrm{A}}\right)\right]
$$

These atmospheric quantities are internally generated when running the model. In this study, the 6SV model was set to MSI bands using a spectral response function. Subsequently, the code was run for each subset of the MAIAC-based atmospheric data according to each lake, applying water vapour $\left(\mathrm{U}_{\mathrm{h}_{2} \mathrm{O}}\right.$, measured in $\left.\mathrm{g} \cdot \mathrm{cm}^{-2}\right)$, ozone content $\left(\mathrm{U}_{\mathrm{O}_{3}}\right.$, measured in $\left.\mathrm{cm} \cdot \mathrm{atm}^{-1}\right)$, aerosol model and AOD at $550 \mathrm{~nm}$ described in Table 2. We selected a biomass burning model based on the global aerosol mixture from Taylor et al. [24], which indicated a dominance of biomass burning particles in August in the Mamirauá region (biomass burning: $72 \%$, Sulphate: $22.8 \%$, Maritime: $2.5 \%$, and Dust: $2.7 \%$ ). The sun angles, date and time of the image acquisition were obtained from the image metadata.

To understand the contribution of the atmosphere and surface to the TOA signal measured by MSI sensor, and to assess the atmospheric effects according to spectral bands, the TOA reflectance was simulated from the above mentioned water reflectance for each lake (Equation (3)). This theoretical TOA reflectance was simulated using the average AOD of August in the lakes (BUA: 0.178; MAM: 0.188; PANTA: 0.181; and PIRA: 0.19), biomass burning model, tropical atmosphere profile, and the average of in-situ reflectances from each lake. 


\subsection{ACOLITE Algorithm}

The Atmospheric Correction for OLI "lite" (ACOLITE) algorithm was developed for the atmospheric correction of OLI/Landsat 8 and MSI/Sentinel 2 images for ocean and inland water studies $[21,54,55]$. The ACOLITE algorithm removes scattering effects of molecular and aerosol components over clear and turbid water. The Rayleigh scattering was corrected using LUTs from the 6SV model, while aerosol scattering was estimated based on the NIR ( 842 and $865 \mathrm{~nm}$ ) bands for clear water and SWIR (1610 and $2130 \mathrm{~nm}$ ) bands for moderate and turbid water [55]. These bands are very useful to decouple the aerosol reflectance, because the water contribution can be assumed to be negligible. Thus, the aerosol reflectance is retrieved at those bands and extrapolated to VNIR wavelengths based on aerosol type $(\varepsilon)$ or on ratio of Rayleigh corrected reflectance in these infrared bands.

The algorithm (version 2016.05.20) allows the user to choose some inputs for the atmospheric correction: (i) derive $\varepsilon$ fixe on scene, per pixel or user-defined; (ii) gain factors for radiometric calibration [56,57]; (iii) atmospheric pressure; (iv) smooth window applied to aerosol reflectance values; and (v) cloud mask threshold (default: 0.0215 on the $1610 \mathrm{~nm}$ band). In our study, atmospheric correction was performed using the SWIR band approach, as recommended for turbid water [55]; aerosol correction per-pixel; a smooth window of 25 pixels; and cloud dilatation of 16 pixels (default).

\subsection{Sen2Cor Algorithm}

The Sentinel 2 MSI data are distributed as ortho-image TOA reflectance products. To derive the MSI land products at Level-2A, the Sentinel toolbox provides the Sen2Cor processor for atmospheric correction and scene classification [20]. As a module of the Sen2Cor algorithm, an operational atmospheric correction is applied to the MSI spectral bands to retrieve atmospheric parameters from the image itself, with cirrus correction in a channel at $1375 \mathrm{~nm}$; water vapour retrieval based on the B8A and $\mathrm{B} 9$ bands $(865,945 \mathrm{~nm})$ and AOD retrieval [58]. Thus, the algorithm performs a semi-empirical approach that associates image-derived atmospheric properties with the pre-computed Look-up table (LUT) from libRadtran radiative transfer model. The advantage of this image-based approach is that is supports the application in regions without climatological information. The spectral relation of the reflectance of B4 $(665 \mathrm{~nm})$ and B2 $(490 \mathrm{~nm})$ bands with B12 $(2190 \mathrm{~nm})$ band is used for the AOD retrievals in reference areas, such as dense dark vegetation (DDV) surfaces [59]. In the Amazon region, DDV surfaces around lakes benefit AOD retrievals due to the strong reflectance relation between visible and SWIR bands and temporal stability in these preserved areas. When these vegetated areas are not available on scene, the algorithm identifies dark soil and water surfaces, or applies a default visibility of $20 \mathrm{~km}$. To run the Sen2Cor algorithm (version 2.2.1), we chose the rural aerosol, ozone content of 330 D.U., smooth window of $100 \times 100 \mathrm{~m}^{2}$ box applied to the water vapour map, and adjacency correction within the $1000 \times 1000 \mathrm{~m}^{2}$ box.

\subsection{Adjacency Effect Correction}

Adjacency effects are an optical-physical process caused by molecular and aerosol scattering where the target view is affected by radiation reflected from neighbourhood surfaces [60]. These multiple scattering regimes of photons from adjacent areas modify the spectral signal of the target pixel. The magnitude of these effects depends on the: (i) atmospheric turbidity, at a particular aerosol scattering phase function; (ii) spectral contrast of the surface reflectance; and (iii) sensor characteristics [61-63]. The influence of atmospheric scattering on adjacency effects increases as a result of the high optical thickness $[64,65]$. This impact produces blurring effects that distort the effective spatial resolution, reduce the apparent surface contrast and affect the land cover characterization $[62,66]$. In case of Sentinel-2 MSI, the actual spatial resolution allows discrimination of small water bodies [67], however, atmospheric scattering might change the effective pixel size and quality of the image according to aerosol microphysical properties (particle-size distribution, composition, and particle 
shapes) and loading [63]. Moreover, the target spectrum is more susceptible to adjacency effects in heterogeneous areas, especially, at high-spatial resolution [68]. In coastal and inland waters, these effects are more evident due to typical lower reflectance in relation to their neighbourhood surfaces, such as sand close to coastal waters and vegetation around reservoirs and lakes [30].

In our study, the large contrast of reflectance between forest and water surfaces contributes to spectral distortions of water-pixels, particularly, in the NIR signal (Figure 4). For example, the water spectrum of the Mamirauá Lake is highly affected by the forest neighbourhood, due to the typical low reflectance $(<1 \%)$ and narrow width $(200-400 \mathrm{~m}$ between margins). Therefore, this phenomenon requires careful evaluation and several studies have proposed solutions (see, for example, Duan et al. [69] and references therein). For example, previous applications derived the contextual information, known as an environmental reflectance function, based on the distance-weighted average reflectance of neighbouring pixels and ratio of direct and diffuse transmittance for adjacency correction $[60,70]$. However, this environmental reflectance is a critical issue when it is applied to areas with significant spectral contrast between surfaces, such as water and land targets [29]. In addition, different procedures were developed based on atmosphere point spread function (PSF) to quantify surrounding contributions and synthesize the filter correction of the neighbouring reflections $[29,69]$. Although these methods are routinely used for adjacency correction, the image-based scheme provides a practical sense for remote sensing users and overcomes limitations of atmospheric parameters that are not always available in remote areas such as the Amazon.
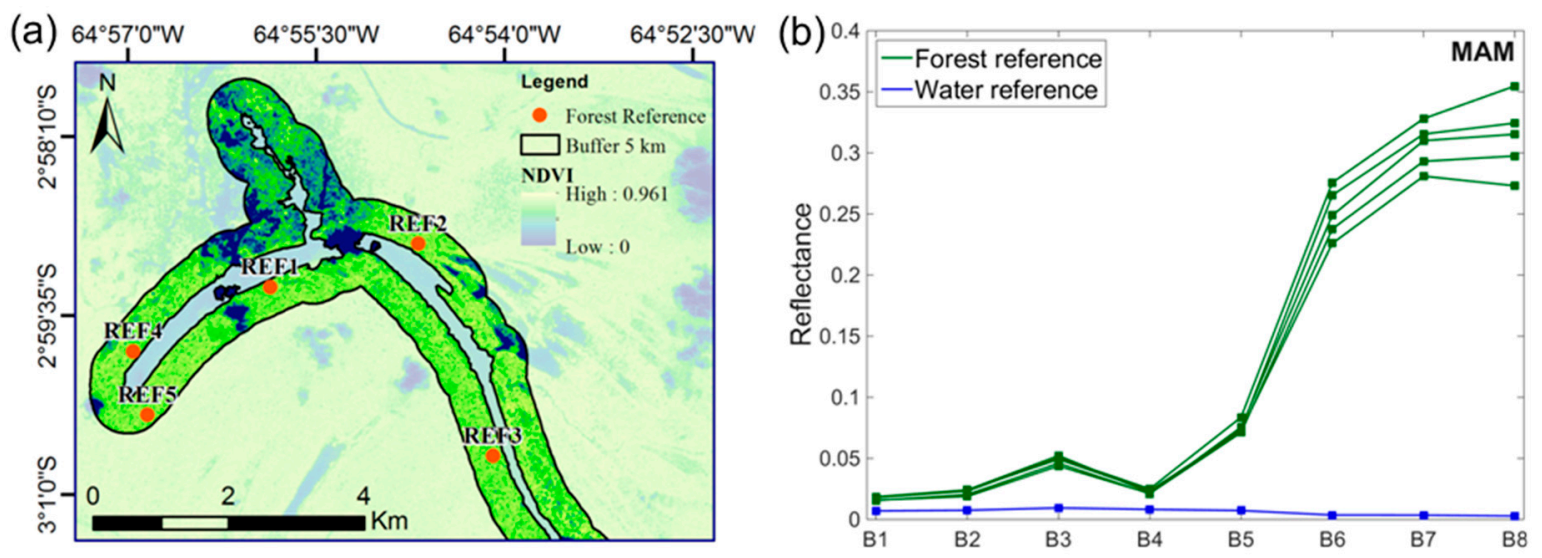

Figure 4. Example of water and forest endmembers selection at Mamirauá Lake. (a) Random points in the forest surface near to Mamirauá Lake. (b) Water and forest endmembers (Table 3).

Since adjacency effect consists of spectral mixing problems, we performed a simple procedure to decouple water and forest contributions using Linear Spectral Unmixing model (LSU) [71]. The main idea of the LSU model is to decompose the surface reflectance contributions of mixed pixels based on the pure spectrum collection of their surfaces, called endmembers. In this sense, mixed spectrum is given by the linear sum of distinct proportion of each endmember (Equation (6)) and LSU model provides fraction maps of surface contributions per pixel [72].

$$
\begin{aligned}
\mathrm{R}_{\mathrm{i}} & =\mathrm{ff}_{1, \mathrm{i}} \times \mathrm{R}_{1, \mathrm{i}}+\mathrm{ff}_{2, \mathrm{i}} \times \mathrm{R}_{2, \mathrm{i}}+\ldots+\mathrm{ff}_{\mathrm{M}, \mathrm{i}} \times \mathrm{R}_{\mathrm{M}, \mathrm{i}}+\mathrm{w} \\
& =\sum_{\mathrm{n}=1}^{\mathrm{M}} \mathrm{ff}_{\mathrm{n}, \mathrm{i}} \times \mathrm{R}_{\mathrm{n}, \mathrm{i}}+\mathrm{w}
\end{aligned}
$$

where $\mathrm{R}$ is the reflectance of pixel, $\mathrm{ff}$ is the contribution fraction, $\mathrm{R}_{\mathrm{M}}$ is the spectral reflectance of endmember (M), $\mathrm{M}$ is the number of endmembers, $\mathrm{w}$ is an error term accounting for additive noise (including sensor noise, endmember variability, and other model inadequacies) and $i=\left[1,2, \ldots, i_{n}\right]$ is the number of spectral bands. 
Briefly, this adjacency correction procedure is described in the following steps: (i) selection of water and forest endmembers as an input for the LSU model; (ii) calculation of the adjacency contribution based on a forest fraction map; and (iii) adjacency removal per water pixel of each lake. The selection of the water endmember is critical when all water-pixels are highly affected by adjacency effects. Thus, two main assumptions were made: (i) prior knowledge of the typical water reflectance as input for the LSU model; and (ii) the forest is the only adjacency surface that distorts the water spectrum. Based on these assumptions, we selected the highest spectrum of each sample station to calculate the average of water reflectance per lake (Table 3). For forest reference, five random spectra were selected over a vegetated area with NDVI $>0.8$ up to $5 \mathrm{~km}$ from the lake (example in Figure 4). The average of these vegetation spectra is referred to as forest endmember per lake (Table 3 ).

After running the LSU model, the forest fraction mapping of the lake was multiplied by forest reference spectrum to estimate adjacency effects for all water-pixels (Equation (7)), which were then removed from the MSI surface reflectance derived from the 6SV model (Equation (8)).

$$
\begin{gathered}
\mathrm{R}_{\mathrm{adj}, \mathrm{i}}\left(\mathrm{x}_{\mathrm{n}}, \mathrm{y}_{\mathrm{n}}\right)=\mathrm{R}_{\text {fpure, }} \mathrm{i} \times \mathrm{ff}_{\mathrm{i}}\left(\mathrm{x}_{\mathrm{n}}, \mathrm{y}_{\mathrm{n}}\right) \\
\mathrm{R}_{\text {cor }^{*}, \mathrm{i}}\left(\mathrm{x}_{\mathrm{n}}, \mathrm{y}_{\mathrm{n}}\right)=\mathrm{R}_{\text {cor, } \mathrm{i}}\left(\mathrm{x}_{\mathrm{n}}, \mathrm{y}_{\mathrm{n}}\right)-\mathrm{R}_{\mathrm{adj}, \mathrm{i}}\left(\mathrm{x}_{\mathrm{n}}, \mathrm{y}_{\mathrm{n}}\right)
\end{gathered}
$$

where $R_{a d j}$ is the forest adjacency effects, $R_{f p u r e}$ is the forest reference spectrum (Table 3 ), ff is the fraction of forest signal affecting the water spectrum, $R_{\text {cor }}$ is the MSI-corrected image from 6SV model, $R_{\text {cor* }}$ is the adjacency corrected image, $x_{n}=\left[x_{1}, \ldots, x_{n}\right]$ is the column of pixel $n, y_{n}=\left[y_{1}, \ldots, y_{n}\right]$ is the row of pixel $n$ over water surface, and $i=[1, \ldots, 8]$ is the number of spectral band. Finally, the adjacency corrected MSI image was also evaluated with in-situ measurements.

Table 3. Water and forest endmembers selected as input to LSU per lake.

\begin{tabular}{cccccccccc}
\hline Lake & Type & B1 & B2 & B3 & B4 & B5 & B6 & B7 & B8 \\
\hline \multirow{2}{*}{ BUA } & Water & 0.005 & 0.006 & 0.008 & 0.007 & 0.006 & 0.002 & 0.002 & 0.002 \\
& Forest & 0.023 & 0.031 & 0.062 & 0.030 & 0.096 & 0.289 & 0.341 & 0.343 \\
\hline \multirow{2}{*}{ MAM } & Water & 0.007 & 0.008 & 0.009 & 0.008 & 0.007 & 0.004 & 0.004 & 0.003 \\
& Forest & 0.017 & 0.022 & 0.048 & 0.023 & 0.075 & 0.251 & 0.306 & 0.313 \\
\hline \multirow{2}{*}{ PANTA } & Water & 0.008 & 0.011 & 0.017 & 0.017 & 0.016 & 0.006 & 0.006 & 0.005 \\
& Forest & 0.009 & 0.015 & 0.042 & 0.019 & 0.072 & 0.249 & 0.300 & 0.296 \\
\hline \multirow{2}{*}{ PIRA } & Water & 0.008 & 0.012 & 0.019 & 0.018 & 0.015 & 0.005 & 0.004 & 0.003 \\
& Forest & 0.017 & 0.023 & 0.050 & 0.025 & 0.077 & 0.253 & 0.312 & 0.329 \\
\hline
\end{tabular}

\section{Results and Discussion}

The results will be presented in the following sequence: (i) validation of MAIAC AOD 550 product in the Amazon region; (ii) seasonal distribution of $\mathrm{AOD}_{550}, \mathrm{U}_{\mathrm{H} 2 \mathrm{O}}$ and cloud cover over the study area; (iii) simulation of the TOA reflectance of the MSI spectral bands; (iv) inter-comparison of three atmospheric methods applied to the MSI image from 12 August 2016; and (v) forest adjacency correction based on the LSU model.

\subsection{Evaluation of $M A I A C A O D_{550}$}

Figure 5 shows a comparison between the average of AERONET measurements within $\pm 30 \mathrm{~min}$ of MODIS overpass and the average of MAIAC AOD 550 within a $25 \times 25 \mathrm{~km}^{2}$ area. The agreement between the satellite and ground measurements was assessed using a linear regression model and the standard expected error (EE) of MODIS atmospheric products (dashed red lines) defined by $\mathrm{AOD}= \pm 0.05 \pm 0.15 \times \mathrm{AOD}[46]$. EE is the number of MAIAC retrievals falling within the standard expected error, and Remer et al. [46] suggested that EE threshold of $66 \%$ represents a satisfactory accuracy of the satellite AOD retrievals. The number of match-ups for Terra (245) was higher than that 
for Aqua (67), due to the difference of the cloud cover between morning and afternoon periods. In general, our results showed that both Terra and Aqua products agree well with AERONET measurements, with both slope of linear regression and correlation coefficient $(\mathrm{R})$ higher than 0.74 . For comparison, the Aqua product presents a slightly better accuracy than that of Terra, with a mean ratio of 1.03 for Aqua and 0.8 for Terra. In this context, forest surfaces represent feasible areas for a strong relation of visible and SWIR bands used for the DDV approach [59] and an increase the sensitivity of aerosol scattering effects in TOA reflectance [73]. Finally, the quality of MAIAC retrievals over the Amazon region are also observed by the number of AOD retrievals falling within standard expected error that presented EE values higher than $66 \%$ threshold (EE is $76.7 \%$ for Terra and $88.1 \%$ for Aqua). To increase the confidence in the AOD product as input for $6 \mathrm{SV}$ atmospheric correction, AOD values obtained from MAIAC Terra were corrected (AODcorrected $=\mathrm{AOD} \times 1 / 0.803$ ) using a mean ratio of 0.803 (see in Figure 5).

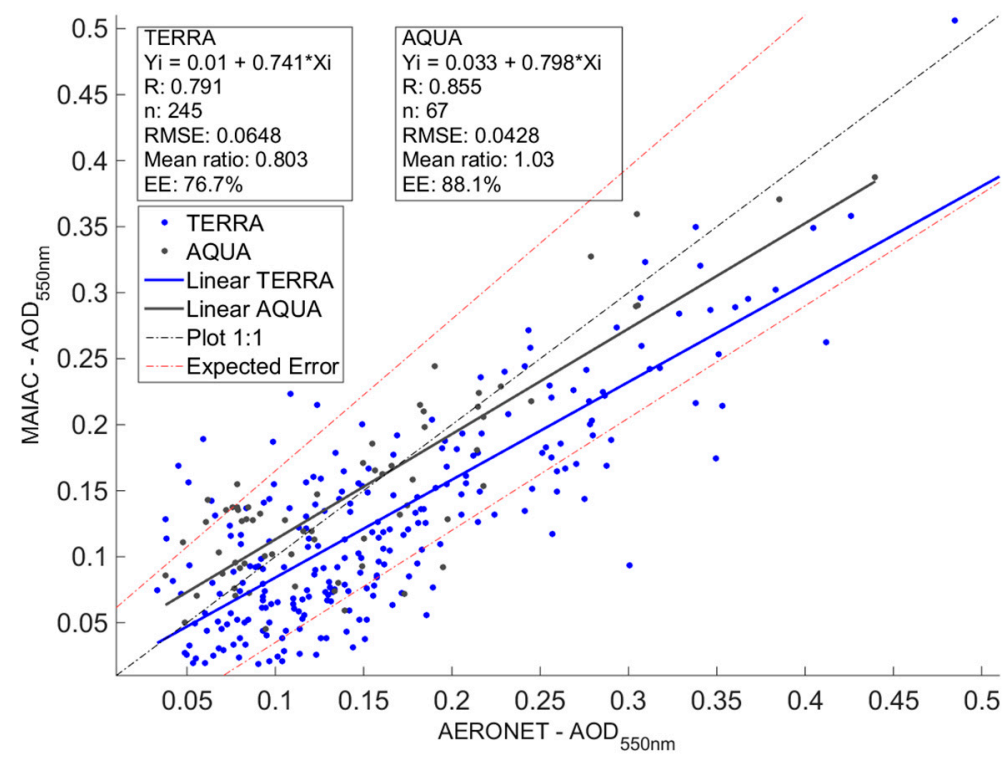

Figure 5. Scatter plot of MAIAC AOD 550 (y-axis) compared to AERONET AOD 550 data (x-axis) from three sites in the Amazon region: Balbina, Belterra and Manaus-Embrapa. Solid blue and grey lines are the linear regression fits for Terra and Aqua, respectively. Red dashed lines are the MODIS standard expected error intervals $(\triangle \mathrm{AOD}= \pm 0.05 \pm 0.15 \times$ AOD) [74]. Text box: Regression equation, correlation coefficient (R), match-ups (n), root mean square error (RMSE), mean ratio $\left(\overline{\mathrm{AOD}}_{\mathrm{MAIAC}} / \overline{\mathrm{AOD}}_{\mathrm{AERONET}}\right)$, and $\mathrm{EE}$ is the number of retrievals falling within standard expected error.

\subsection{Background of Atmospheric Constituents}

The seasonal variability of atmospheric constituents imposes distinct conditions for atmospheric correction and the background information of these constituents is desirable to understand the effects on remote sensing data [75]. Figure 6 presents the monthly average of $\mathrm{AOD}_{550}, \mathrm{U}_{\mathrm{H}_{2} \mathrm{O}}$ and cloud cover frequency using 15-year MAIAC Terra products in the study area (red box in Figure 1). The results showed that atmospheric components have distinct patterns between the first and second half of the year. In the first half of the year, high frequency cloud cover $(\sim 9 \%)$ was observed, which restricts continuous remote sensing observations of the Mamirauá region in this particular period. However, the probability of cloud-free images increases in July, August, and October, when the cloud cover decreased to $60 \%-80 \%$. Hilker et al. [76] also reported an increase of cloud-free pixels $(40 \%-60 \%)$ in June, July and August based on MAIAC Terra observations from 2007 over the Amazon region and pointed out MAIAC improvements to detect small cloud-free areas compared with the previous MOD09 product. Under these conditions, the temporal resolution of Sentinel 2 MSI images has the potential to increase the probability of cloud-free images over this tropical region thanks to a high 
five-day revisit scheduled for 2017. In parallel with cloud cover, AOD presents a remarkable seasonal variation in the first and second half of the year. In general, a low AOD (0.02-0.18) is typically observed throughout the year, however, the first half of the year registers the lowest AOD values (0.1-0.14), while the AOD values increase to 0.16-0.18 between August and November. Castro et al. [77] also found typical low AOD values in the Northern Amazon region (see TD1 region), and illustrated the variability between the first and second half of the year caused by local fires. Fires are the cheapest and most effective way for local communities to clear areas in order to introduce pasture and agricultural cultures [78] and can be intentionally used to dissipate insect pests. Therefore, the temporal variation of AOD values imposes particular conditions for atmospheric correction depending on the period, and needs further attention during the second half of the year.

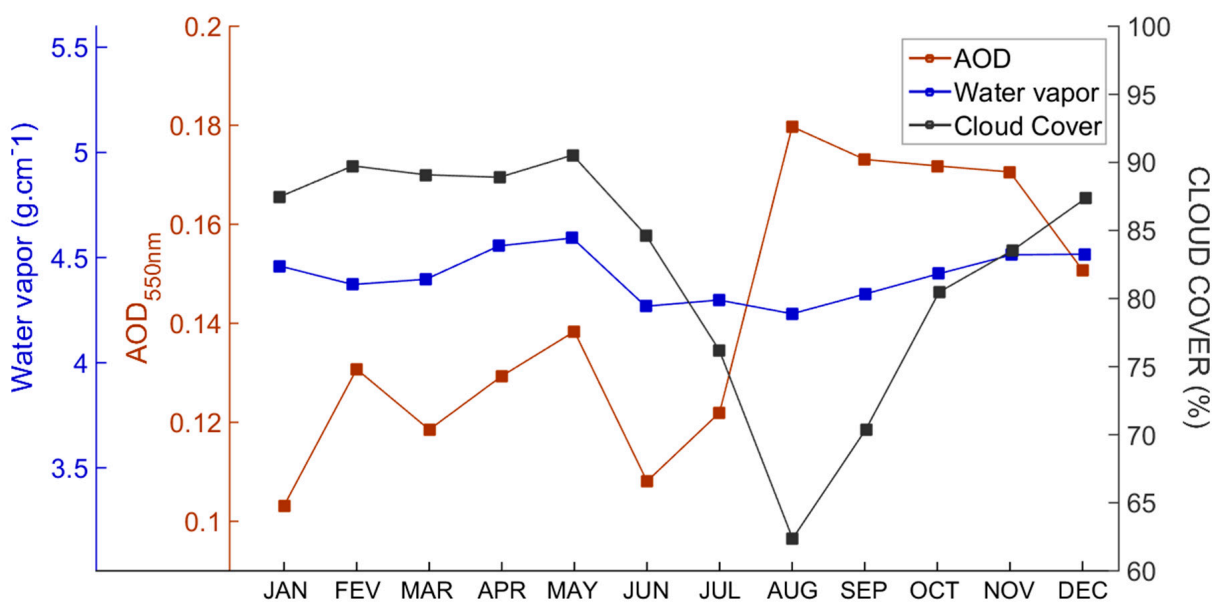

Figure 6. Monthly average of aerosol optical depth (AOD) at $550 \mathrm{~nm}$, water vapour content and cloud cover from MAIAC Terra (2000-2015) in Mamirauá region (see red-box in Figure 1).

The Mamirauá region has high concentrations of water vapour $\left(4.2-4.7 \mathrm{~g} / \mathrm{cm}^{2}\right)$, with quasi-permanent concentration throughout the year. Vermote et al. [70] showed that $\mathrm{U}_{\mathrm{H} 2 \mathrm{O}}$ content (variation of $0.5-4.1 \mathrm{~g} / \mathrm{cm}^{2}$ ) implicates on higher atmospheric effects on the reflectance magnitude in the NIR region $(3.4 \%-14.0 \%)$ than those for visible bands $(0.5 \%-3.0 \%)$ of the Landsat 5 TM bands. Therefore, remote sensing applications using NIR bands should consider the temporal variability of this constituent, for example to vegetation indices. Our field campaign was performed during August, with the lowest cloud cover conditions $(\sim 62 \%)$ of the year, despite facing the highest AOD and water vapour concentrations. To better understand the atmospheric and surface contributions, we conducted a TOA simulation using the average AOD over the four lakes for the dataset from August, as shown in Section 4.3 .

\subsection{TOA Simulation Analysis}

The contribution of atmosphere and surface reflectance from four Amazonian lakes to the TOA reflectance of MSI spectral bands was simulated using the AOD average of August (Figure 7). The major fraction of theTOA signal is due to atmospheric effects, whose contribution is higher than $75 \%$ and $50 \%$ over dark and bright lakes, respectively, for all MSI spectral bands. Because atmospheric scattering effects exponentially decay from shorter to longer wavelengths [79], deep blue and blue bands are affected the most by atmospheric signals-representing more than $84 \%$ of TOA reflectance. The highest lake surface contribution was observed for red (B4) and red-edge (B5) bands, where the scattering of suspended inorganic particles in the water column increases surface reflectance, which reached $\sim 43 \%$ of the TOA reflectance in the Panta-leão Lake. On the other hand, the contribution of dark lakes to TOA reflectance reduced dramatically, mainly in the deep blue band, when compared with bright lakes. For example, the Buá-Buá reflectance had a critical fraction that reached $\sim 4.8 \%$ in the deep 
blue band, which clearly shows the difficulty in accurately removing of atmospheric effects over these low-reflectance surfaces. These results suggest that caution is required when the TOA reflectance band ratio is used to retrieve water quality parameters, even when the algorithms present a better correlation using the TOA reflectance compared with surface reflectance [45]. The atmospheric effects among the bands are quite different, and band ratio therefore does not remove all atmospheric effects.

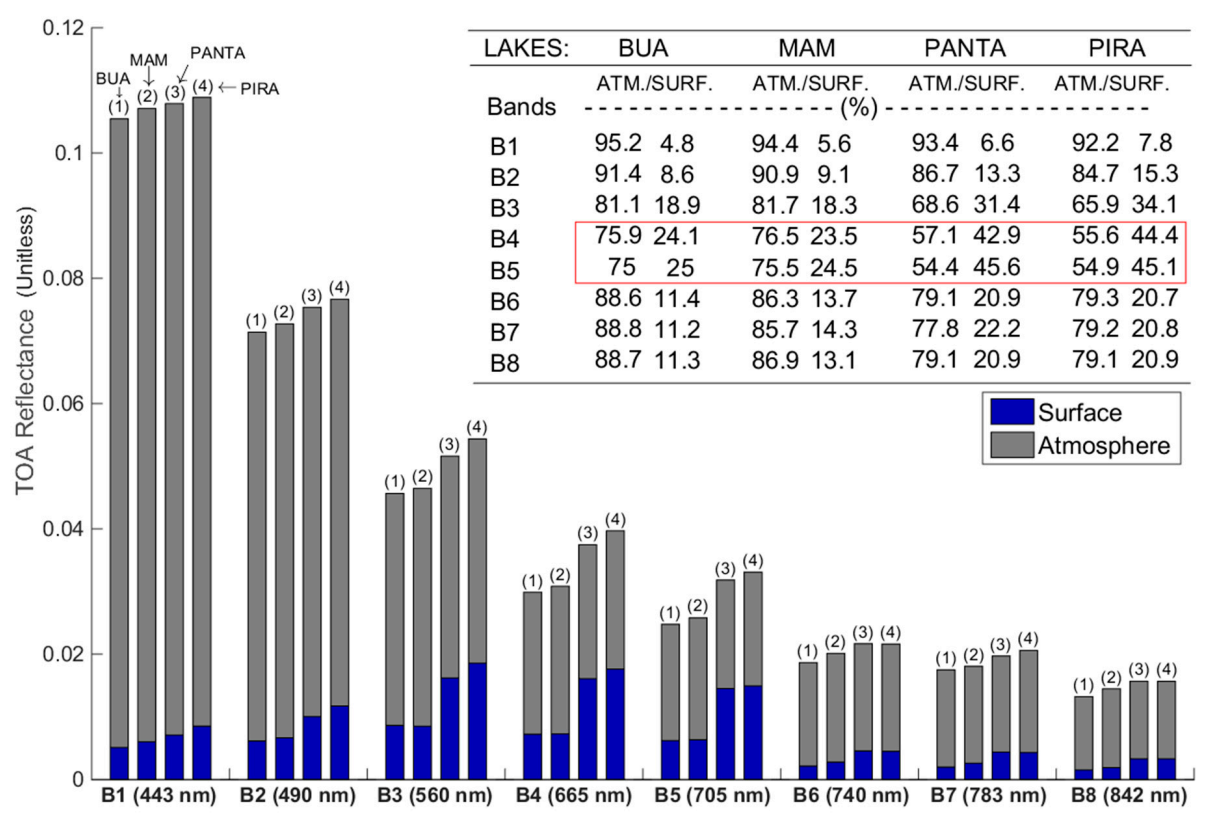

Figure 7. Simulation of TOA reflectance based on month average AOD in August (biomass burning model) and average of water reflectance from four Amazon floodplain lakes. The table at the top right shows the percentage of atmospheric and surface contribution in TOA reflectance simulated for MSI VNIR bands.

In fact, the atmospheric correction is a challenging issue for water quality studies, because inaccuracies of the surface reflectances propagate errors to water quality retrievals. For example, the mapping of CDOM concentration using blue and green bands [80] requires an efficient removal of scattering effects of these (most affected) bands, where atmospheric effects can contribute up to $80 \%$ of the TOA signal over dark lakes. On the other hand, red and red-edge bands applied to model TSS concentrations are less affected by atmospheric effects [81]. These examples thus illustrate that OACs modelling also requires a better understanding of atmospheric optical properties to derive accurate surface products.

\subsection{Inter-Comparison of Atmospheric Correction Methods}

The atmospheric correction performances of three algorithms were assessed using the mean ratio $\left(\overline{\mathrm{R}}_{\text {sur }} / \overline{\mathrm{R}}_{\mathrm{w}, \text { situ }}\right)$ and root mean square error (RMSE). The performances are better when the mean ratio is close to unity and RMSE is low. The mean ratio also expresses a relative error, when the values are higher than 2 , or relative error is $100 \%$, exceed the maximum bias accepted here. This threshold is important for bio-optical models, because the high inaccuracy of the reflectance affects, for example, the COA retrievals (see Odermatt et al. [82] for distinct bio-models).

Figure 8 presents the comparison of the in-situ measurements acquired at four Amazon floodplain lakes with spectra results from the three atmospheric correction methods, while Figure 9 describes the algorithm performance based on the mean ratio and RMSE. The three methods were capable of removing most of the atmospheric effects, where the reflectance magnitude mainly changed from TOA reflectance of $\sim 12 \%-14 \%$ to surface of $\sim 1 \%-2 \%$ of the deep blue and blue bands (Figure 8 ). Before atmospheric correction, TOA reflectance was a typical exponential spectrum dominated by Rayleigh 
and aerosol scattering effects. After correction, even with caveats, the MSI-corrected spectra (dark blue lines in Figure 8) presented a shape close to that of the in-situ measurements (light blue lines in Figure 8). The results showed that the quality of the MSI-corrected reflectance varies depending on the atmospheric correction method, spectral band, and lake characteristics.

In general, Sen2Cor produced the smallest overall RMSE and the best MSI-corrected shape compared with in-situ data (Figure 9), while the spectral shape of ACOLITE showed a bias varying per sample station. The 6SV method provided a quite similar spectral shape in the visible region for bright lakes (RMSE < 0.006), but the reflectance magnitude was higher than that of the in-situ measurements (Figure 9c). Regarding the comparison among lakes, the MSI-corrected reflectance of bright lakes is closer to that of the in-situ measurements than to that of dark lakes; all methods have a mean ratio of $\sim 0.5-1.5$ in the visible bands (Figure $9 \mathrm{a}-\mathrm{c}$ ).
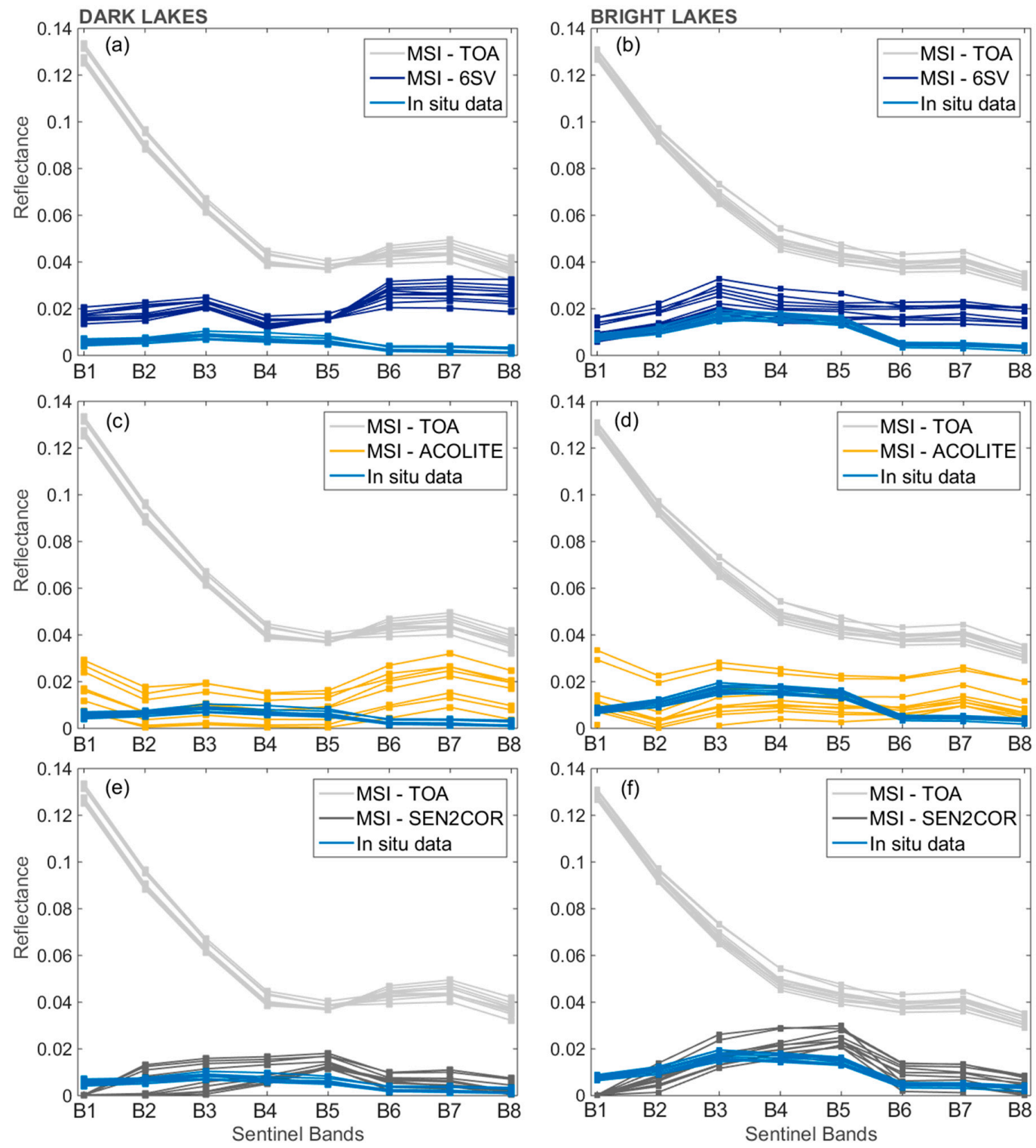

Figure 8. Comparison between MSI reflectance simulated from in-situ measurements, MSI TOA reflectance and MSI-corrected reflectance from three methods: 6SV model based on MAIAC product $(\mathbf{a}, \mathbf{b})$; ACOLITE $(\mathbf{c}, \mathbf{d})$; and Sen2Cor $(\mathbf{e}, \mathbf{f})$. The left column shows reflectance spectra from dark lakes (Buá-Buá and Mamirauá) and, the right column shows reflectance spectra from bright (Pirarara and Panta-Leão) lakes. 
a
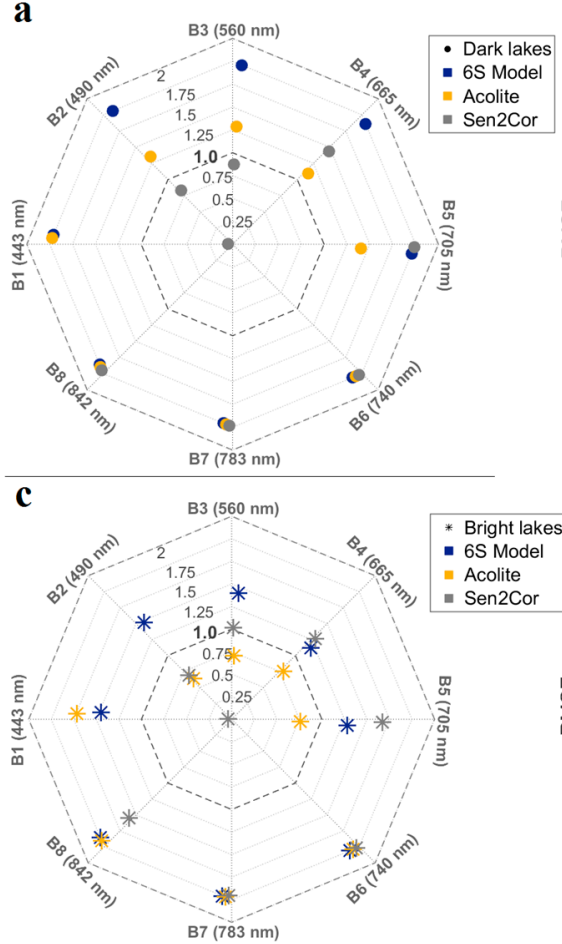

b DARK
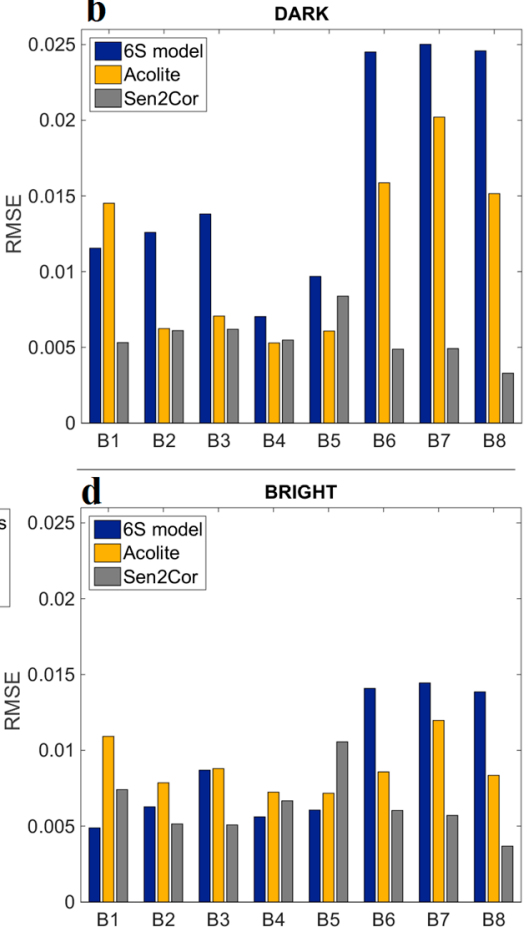

Figure 9. The mean ratio and RMSE for atmospheric correction methods from: dark lakes $(\mathbf{a}, \mathbf{b})$; and bright lakes (c,d). The left column shows the mean ratio $\left(\overline{\mathrm{R}}_{\text {sur }} / \overline{\mathrm{R}}_{\mathrm{W} \text {,situ }}\right)$, with better cases being close to unity, and the right column shows the root mean square error (RMSE). Note that all mean ratio values higher than maximum bias accepted here are represented as 2.

In dark lakes, ACOLITE and Sen2Cor showed quite similar RMSE values in the blue, green and red bands (RMSE 0.006) (Figure 9b), while 6SV was clearly limited under these low reflectance conditions (RMSE 0.011), with a mean ratio exceeding the maximum threshold $(>2)$ for all spectral bands (Figure 9a). In contrast, the MSI-reflectance corrected by the 6SV model had a lower RMSE ( 0.006) and mean ratio of $\sim 1.2-1.50$ (overestimation) in the visible bands over bright lakes, compared with the in-situ measurements (Figure 9c). The generic design of 6SV model includes standard aerosol types for land applications, such as biomass burning, urban, continental, desert, and maritime. Bassani et al. [83] highlighted the impact of the reflectance accuracy on coastal water when the standard 6SV aerosol use does not characterize the local aerosol microphysics. In our case, a complex mixture of natural biogenic and biomass burning particles over the central Amazon [78] imposes a constraint for standard aerosol use, which might explain some limitations of the radiative transfer simulation in order to remove atmospheric effects. In addition, satellite aerosol retrievals are susceptive to several uncertainty sources, such as sensor calibration, cloud screen, aerosol models and surface properties [84], which also help to explain the errors derived from the $6 \mathrm{SV}$ correction based on MAIAC product. Since most bio-optical models apply water surface reflectance mainly to visible bands (B1-B5) [8], Sen2Cor and 6SV results produce a reasonable spectral shape compared with the in-situ measurements for bright lakes; although they overestimate the reflectance magnitude (Figure $8 \mathrm{~b}-\mathrm{f}$ ).

In the visible bands, the ACOLITE method produced a distinct reflectance accuracy among the lakes, where water reflectance was overestimated (mean ratio $\sim 1.1-1.5$, except for B1) for dark lakes (Figure 9a) and underestimated (mean bias $~ 0.63-0.8$, except for B1) for bright lakes (Figure 9c). A strong influence of the per-pixel correction was also observed; the random spatial error contributed to biases in the MSI-corrected reflectance for each sample station, while the 6SV produced a spatially correlated error due to the assumption of homogeneous atmospheric effects on lakes. The ACOLITE-SWIR approach requires a high signal-to-noise ratio (SNR) for the accurate 
quantification of the aerosol effect on TOA reflectance particularly because the effective aerosol scattering is relatively lower at longer wavelengths [85] and accurate aerosol reflectance can be affected by a low SNR. Thus, the propagation of noisy aerosol reflectance from SWIR bands (SNR of 100, see Table 1) to the atmospheric correction of visible bands might explain the spatial variability of error in ACOLITE reflectance retrievals. Therefore, an optional smooth window applied to SWIR bands becomes essential to filter and minimize undesirable effects [21]. Although the ACOLITE produced variable errors in this study, the algorithm has been extensively used for the atmospheric correction of OLI images with satisfactory experiences in coastal and maritime water, for example, sediment plume mapping in the Florida offshore, USA [86], and for turbidity quantification in the Wadden Sea, Germany [87]. Our assessment represents preliminary experience with ACOLITE applied to Sentinel 2 MSI over floodplain water, and further evaluations could contribute to consolidate this image-based approach.

The Sen2Cor algorithm achieves very similar errors for both types of lakes, with RMSE between $\sim 0.003-0.011$ for all spectral bands (Figure $9 \mathrm{~b}-\mathrm{d}$ ), and better mean ratio for blue, green and red bands (grey marker in Figure 9a-c). In fact, the presence of dense forest close to Amazon floodplain lakes provides feasible areas required for DDV application used by the Sen2Cor algorithm. Although an extensive validation has not been performed yet, first results of the comparison between Sen2Cor AOD retrievals over DDV areas and ground measurements led to an AOD uncertainty of about 0.03 [88], which affects the atmospheric correction accuracy of Sen2Cor algorithm. Toming et al. [12] found the shape similarity of MSI-corrected dataset using the Sen2Cor algorithm compared with a historical dataset (2011-2013), although the MSI reflectance spectra were overestimated by the algorithm. In the Amazon context, the presence of forest surfaces benefits AOD retrievals by the Sen2Cor algorithm, however, this surface neighbour also implies in severe adjacency contamination on the water spectrum measured by orbital sensors.

\subsection{Adjacency Effect Correction}

Large differences between forest and water reflectance contribute to strong adjacency effects on the water spectrum in the NIR region. For spectral bands above $705 \mathrm{~nm}$, Sen2Cor correction minimizes the adjacency effects over dark lakes leading to a lower RMSE $(<0.005)$ compared with ACOLITE and 6SV (RMSE > 0.013) (Figure 9b-d). Nevertheless, none of the methods presented a suitable performance to remove forest adjacency effects in the NIR region, with a mean ratio exceeding 2 (Figure 9a-c). Dornhofer et al. [11] evaluated the Sen2Cor and ACOLITE performances for bio-optical models in marine water and found an underestimation of the surface reflectance in the visible region for both methods and adjacency effects on the NIR bands due to sand surface of the shoreline. The adjacency correction applied by Sen2Cor is limited over low reflectance surfaces; methods focusing on water surfaces are required for a high spatial resolution [69].

Figure 10 presents the adjacency correction based on LSU model applied to the MSI water reflectance from dark and bright lakes. The results showed that the adjacency correction improves the quality of water reflectance of all spectral bands. In both dark and bright lakes, MSI reflectance exhibits a better agreement with in-situ measurements, especially for MSI bands above $705 \mathrm{~nm}$ (B6-B8), where the RMSE decreases from $\sim 0.023$ to lower than 0.006 in dark lakes and from $\sim 0.015$ to lower than 0.004 in bright lakes (Figure 10). Evidently, the LSU approach solves the unmixing problem of the water spectrum and reduces the discrepancy caused by forest adjacency. However, note that results have limitations to an extensive application, because we assume that only the forest surface causes adjacency effects and the water endmember was based on prior knowledge of radiometric collection over lakes. These assumptions limit the operational correction to reservoir and lakes with historical radiometric collection or to cases where water endmember can be derived from the image itself. Furthermore, adjacency effects typically depend on the surface types in the scene, which makes it reasonable to consider that unmixing problems are caused by other surfaces. Recently, Sterckx et al. [30] proposed a generic-sensor adjacency correction based on the NIR similarity spectrum 
for water studies, and showed positive or neutral effects on the reflectance accuracy depending on environmental conditions. In general, adjacency correction is a complex procedure that should consider a variety of environmental conditions. Our positive experience using the LSU model is a preliminary assessment to advance towards a more sophisticated image-based approach.
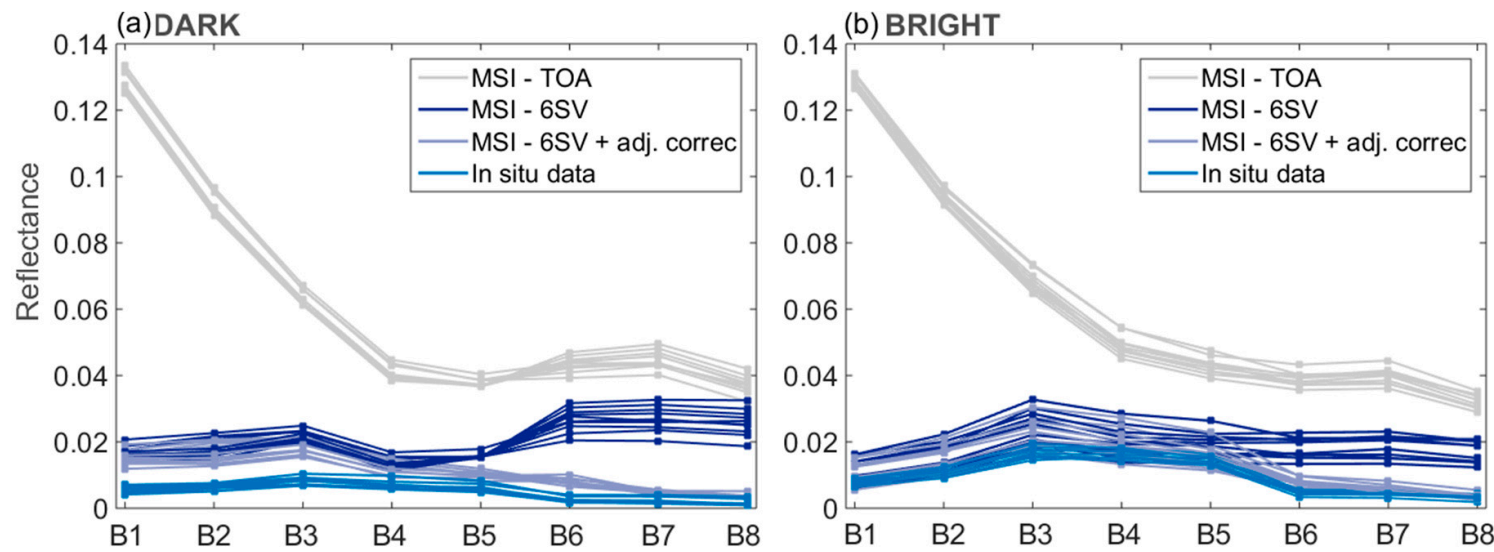

(c) DARK

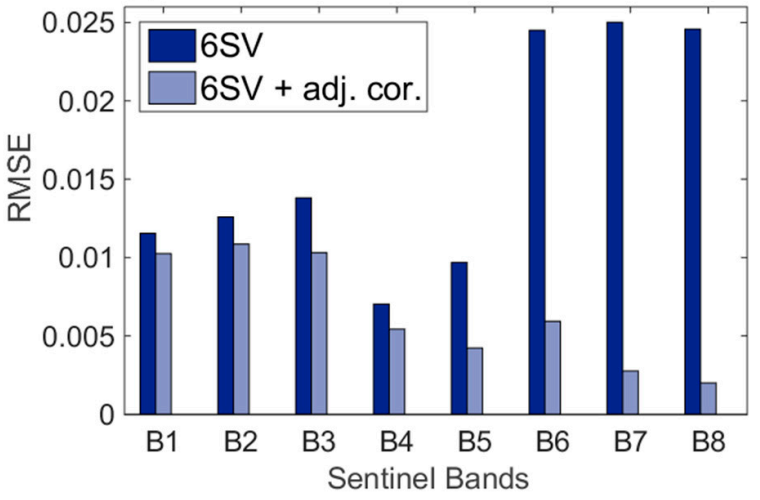

(d)BRIGHT

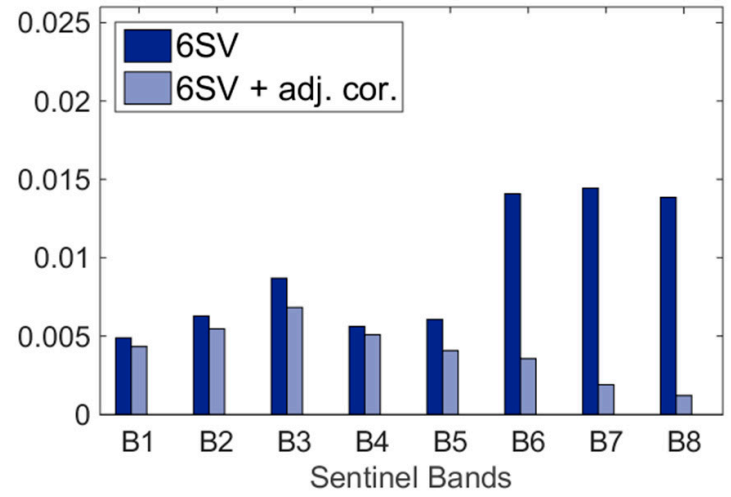

Figure 10. Comparison between MSI TOA reflectance (grey), MSI-corrected reflectance from 6SV model (dark blue), and MSI-adjacency corrected reflectance (purple) and MSI reflectance simulated from in-situ measurements (light blue) from dark $(\mathbf{a}, \mathbf{c})$ and bright lakes $(\mathbf{b}, \mathbf{d})$. RMSE bars before (6SV) and after adjacency correction (6SV + adj. cor.) applied to MSI image from 12 August 2016.

\section{Conclusions}

Sentinel 2 MSI images represent a new opportunity for monitoring small inland aquatic systems. However, to derive an accurate surface reflectance over complex water and consequently produce better water quality products, efforts must focus on the development of efficient atmospheric correction methods. Although our results present a variation in the surface reflectance accuracy along the spectral range, it is important to highlight the complexity of environmental condition in our study area, such as the water reflectance $(<2 \%)$, narrow and irregular lakes, low spatial variability and strong influence of the adjacency forest.

In terms of the temporal variation of atmospheric constituents (cloud cover, $\mathrm{AOD}$ and $\mathrm{U}_{\mathrm{H}_{2} \mathrm{O}}$ ) within the study area, high cloud cover ( $90 \%)$ limits the cloud-free image during the first half of the year. The cloud cover decreases in the second half of the year $(60 \%-80 \%)$, while AOD increases from $\sim 0.12$ to $\sim 0.18$ and water vapour remains constant $\sim 4.4 \mathrm{~g} / \mathrm{cm}^{2}$ between seasons. The fine resolution of MAIAC AOD product has an acceptable accuracy to support radiative transfer models in the Amazon region. The simulation of the TOA reflectance clearly shows an inherent difficulty faced by inland water studies, because the atmospheric contribution varies from $\sim 50 \%$ to $\sim 94 \%$ of TOA signal according to spectral band. 
The atmospheric correction methods present a notable variation in the MSI-corrected accuracy along spectral bands depending on lake characteristics. For dark lakes, the results indicate method limitations to derive an accurate reflectance spectrum, particularly above $705 \mathrm{~nm}$ due to forest adjacency effects. In the visible bands, Sen2Cor and ACOLITE showed quite similar RMSEs for dark lakes whereas the 6SV model exhibited better results for bright lakes. Therefore, the selection of an atmospheric correction method needs to be aligned with the study purposes and user expertise to apply these tools, since our results present advantages and disadvantages of different methods for the reflectance shape and magnitude accuracy.

All methods showed limitations in the accurate retrievals in the NIR region due to forest adjacency effects. The performance of the adjacency correction using the LSU model improved the quality of MSI-corrected reflectance and derived better spectra shape compared with the in-situ measurements. However, there are constraints for operational application, such as selection of the water endmember and other adjacent surfaces, which need to be taken into account when applying the method to different contexts/regions. Therefore, this experience is considered to be a preliminary assessment to advance on image-based approaches to remove adjacency effects.

The assessment of these atmospheric correction methods has an inherent challenge due to the shortage of cloud-free images and the limitations of routine in-situ measurements. However, even for a single Sentinel-2 image, it was possible to explore the available methods applied to complex environmental conditions (low water reflectance, forest adjacency effects and seasonal variability of aerosol atmospheric), such as in the Amazon region. We recommend an extensive validation for distinct water types and atmospheric conditions to further understand the potential and limitations of these atmospheric correction methods.

Acknowledgments: This study was funded by São Paulo Research Foundation (FAPESP) from project no.: 2014/23903-9 and MSA-BNDES from project no.: 1022114003005. V. Martins was funded by the Coordination for the Improvement of Higher Education Personnel (CAPES) Program. E. Novo acknowledges for the research productivity fellowship CNPQ 304568/2014-7. We are very grateful to Renato Ferreira and Adriana Affonso for their assistance and logistical support during field campaign. We would like to thank ESA team for providing free Sentinel-2A data and Sen2Cor processor. We further thank Vanhellemont and RBIN team for the development and distribution of ACOLITE algorithm. We also thank Wilson Robin for providing Py6S (Python interface to 6SV) with full description of package [89]. We thank AERONET PIs, Brent Holben, Paulo Artaxo and their staffs, for establishing and maintaining the AERONET site at Balbina, Belterra and Manaus-Embrapa. Al last, we thank Alexei Lyapustin and Yugie Wang for the updating of MAIAC dataset over Amazon. The MSI response spectral function is available at https://sentinel.esa.int/documents/247904/685211/Sentinel-2A+MSI+Spectral+ Responses. We thank the anonymous reviewers for their effort and helpful comments.

Author Contributions: Vitor Martins, Claudio Barbosa, Lino de Carvalho, Daniel Jorge, Felipe Lobo and Evlyn Novo designed the research. Vitor Martins performed the data processing, atmospheric correction and validation, as well as wrote the paper. Claudio Barbosa, Lino de Carvalho and Daniel Jorge were involved in the collection of field data. Claudio Barbosa and Lino de Carvalho supported the processing of in-situ measurements. Felipe Lobo and Evlyn Novo contributed with insights about analysis and methods. All authors equally contributed towards organizing and reviewing the manuscript.

Conflicts of Interest: The authors declare no conflict of interest.

\section{References}

1. Dudgeon, D.; Arthington, A.H.; Gessner, M.O.; Kawabata, Z.-I.; Knowler, D.J.; Lévêque, C.; Naiman, R.J.; Prieur-Richard, A.-H.; Soto, D.; Stiassny, M.L.J.; et al. Freshwater biodiversity: Importance, threats, status and conservation challenges. Biol. Rev. 2006, 81, 163-182. [PubMed]

2. Vörösmarty, C.J.; McIntyre, P.B.; Gessner, M.O.; Dudgeon, D.; Prusevich, A.; Green, P.; Glidden, S.; Bunn, S.E.; Sullivan, C.A.; Liermann, C.R.; et al. Global threats to human water security and river biodiversity. Nature 2010, 467, 555-561. [CrossRef] [PubMed]

3. Abell, R.; Thieme, M.L.; Revenga, C.; Bryer, M.; Kottelat, M.; Bogutskaya, N.; Coad, B.; Mandrak, N.; Balderas, S.C.; Bussing, W.; et al. Freshwater ecoregions of the world: A new map of biogeographic units for freshwater biodiversity conservation. Bioscience 2008, 58, 403-414. [CrossRef] 
4. Mertes, L.; Smith, M.; Adams, J. Estimating suspended sediment concentrations in surface waters of the Amazon River wetlands from Landsat images. Remote Sens. Environ. 1993, 43, 281-301. [CrossRef]

5. Park, E.; Latrubesse, E.M. Modeling suspended sediment distribution patterns of the Amazon River using MODIS data. Remote Sens. Environ. 2014, 147, 232-242. [CrossRef]

6. Lobo, F.L.; Costa, M.P.F.; Novo, E.M.L.M. Time-series analysis of Landsat-MSS/TM/OLI images over Amazonian waters impacted by gold mining activities. Remote Sens. Environ. 2014, 157, 170-184. [CrossRef]

7. Espinoza Villar, R.; Martinez, J.M.; Guyot, J.L.; Fraizy, P.; Armijos, E.; Crave, A.; Bazán, H.; Vauchel, P.; Lavado, W. The integration of field measurements and satellite observations to determine river solid loads in poorly monitored basins. J. Hydrol. 2012, 444, 221-228. [CrossRef]

8. Bukata, R.P.; Jerome, J.H.; Kondratyev, A.S.; Pozdnyakov, D.V. Optical Properties and Remote Sensing of Inland and Coastal Waters; CRC Press: Boca Raton, FL, USA, 1995.

9. Palmer, S.C.J.; Kutser, T.; Hunter, P.D. Remote sensing of inland waters: Challenges, progress and future directions. Remote Sens. Environ. 2015, 157, 1-8. [CrossRef]

10. Drusch, M.; Del Bello, U.; Carlier, S.; Colin, O.; Fernandez, V.; Gascon, F.; Hoersch, B.; Isola, C.; Laberinti, P.; Martimort, P.; et al. Sentinel-2: ESA's Optical High-Resolution Mission for GMES Operational Services. Remote Sens. Environ. 2012, 120, 25-36. [CrossRef]

11. Dörnhöfer, K.; Göritz, A.; Gege, P.; Pflug, B.; Oppelt, N. Water Constituents and Water Depth Retrieval from Sentinel-2A-A First Evaluation in an Oligotrophic Lake. Remote Sens. 2016, 8, 941. [CrossRef]

12. Toming, K.; Kutser, T.; Laas, A.; Sepp, M.; Paavel, B.; Nõges, T. First Experiences in Mapping Lake Water Quality Parameters with Sentinel-2 MSI Imagery. Remote Sens. 2016, 8, 640. [CrossRef]

13. Hedley, J.; Roelfsema, C.; Koetz, B.; Phinn, S. Capability of the Sentinel 2 mission for tropical coral reef mapping and coral bleaching detection. Remote Sens. Environ. 2012, 120, 145-155. [CrossRef]

14. Malthus, T.J.; Hestir, E.L.; Dekker, A.G.; Brando, V.E. The case for a global inland water quality product. In Proceedings of the 2012 IEEE International Geoscience and Remote Sensing Symposium, Munich, Germany, 22-27 July 2012; pp. 5234-5237.

15. Malenovský, Z.; Rott, H.; Cihlar, J.; Schaepman, M.E.; García-Santos, G.; Fernandes, R.; Berger, M. Sentinels for science: Potential of Sentinel-1, -2 , and -3 missions for scientific observations of ocean, cryosphere, and land. Remote Sens. Environ. 2012, 120, 91-101. [CrossRef]

16. Gao, B.C.; Montes, M.J.; Davis, C.O.; Goetz, A.F.H. Atmospheric correction algorithms for hyperspectral remote sensing data of land and ocean. Remote Sens. Environ. 2009, 113, S17-S24. [CrossRef]

17. International Ocean Colour Coorperating Group (IOCCG). Atmospheric Correction for Remotely-Sensed Ocean-Colour Products; International Ocean Colour Coorperating Group (IOCCG): Cape Town, South Africa, 2010.

18. Okin, G.S.; Gu, J. The impact of atmospheric conditions and instrument noise on atmospheric correction and spectral mixture analysis of multispectral imagery. Remote Sens. Environ. 2015, 164, 130-141. [CrossRef]

19. Hadjimitsis, D.G.; Clayton, C.R.I.; Hope, V.S. An assessment of the effectiveness of atmospheric correction algorithms through the remote sensing of some reservoirs. Int. J. Remote Sens. 2004, 25, 3651-3674. [CrossRef]

20. Main-Knorn, M.; Pflug, B.; Debaecker, V.; Louis, J. Calibration and validation plan for the L2A processor and products of the Sentinel-2 Mission. ISPRS Int. Arch. Photogramm. Remote Sens. Spat. Inf. Sci. 2015, 40, 1249-1255. [CrossRef]

21. Vanhellemont, Q.; Ruddick, K. Acolite for Sentinel-2: Aquatic applications of MSI imagery. In Proceedings of the ESA Living Planet Symposium, Pragur, Czech Republic, 9-13 May 2016.

22. Shi, W.; Wang, M. An assessment of the black ocean pixel assumption for MODIS SWIR bands. Remote Sens. Environ. 2009, 113, 1587-1597. [CrossRef]

23. Vermote, E.F.; Tanré, D.; Deuzé, J.L.; Herman, M.; Morcrette, J.J. Second simulation of the satellite signal in the solar spectrum, 6S: An overview. IEEE Trans. Geosci. Remote Sens. 1997, 35, 675-686.

24. Taylor, M.; Kazadzis, S.; Amiridis, V.; Kahn, R.A. Global aerosol mixtures and their multiyear and seasonal characteristics. Atmos. Environ. 2015, 116, 112-129. [CrossRef]

25. Holben, B.N.; Eck, T.F.; Slutsker, I.; Tanré, D.; Buis, J.P.; Setzer, A.; Vermote, E.; Reagan, J.A.; Kaufman, Y.J.; Nakajima, T.; et al. AERONET-A federated instrument network and data archive for aerosol characterization. Remote Sens. Environ. 1998, 66, 1-16. [CrossRef] 
26. King, M.D.; Menzel, W.P.; Kaufman, Y.J.; Tanre, D.; Gao, B.-C.; Platnick, S.; Ackerman, S.A.; Remer, L.A.; Pincus, R.; Hubanks, P.A. Cloud and aerosol properties, precipitable water, and profiles of temperature and water vapor from MODIS. IEEE Trans. Geosci. Remote Sens. 2003, 41, 442-458. [CrossRef]

27. Lyapustin, A.; Wang, Y.; Laszlo, I.; Kahn, R.; Korkin, S.; Remer, L.; Levy, R.; Reid, J.S. Multiangle implementation of atmospheric correction (MAIAC): 2. Aerosol algorithm. J. Geophys. Res. Atmos. 2011, 116, 1-15. [CrossRef]

28. Hilker, T.; Lyapustin, A.I.; Tucker, C.J.; Sellers, P.J.; Hall, F.G.; Wang, Y. Remote sensing of tropical ecosystems: Atmospheric correction and cloud masking matter. Remote Sens. Environ. 2012, 127, 370-384. [CrossRef]

29. Kiselev, V.; Bulgarelli, B.; Heege, T. Sensor independent adjacency correction algorithm for coastal and inland water systems. Remote Sens. Environ. 2015, 157, 85-95. [CrossRef]

30. Sterckx, S.; Knaeps, S.; Kratzer, S.; Ruddick, K. SIMilarity Environment Correction (SIMEC) applied to MERIS data over inland and coastal waters. Remote Sens. Environ. 2015, 157, 96-110. [CrossRef]

31. Ramalho, E.E.; Macedo, J.; Vieira, T.M.; Valsecchi, J.; Calvimontes, J.; Marmontel, M.; Queiroz, H.L. Ciclo hidrológico nos ambientes de várzea. Uakari 2009, 5, 61-87.

32. Affonso, A.G.; Queiroz, H.L.; Novo, E.M.L.M. Abiotic variability among different aquatic systems of the central Amazon floodplain during drought and flood events. Braz. J. Biol. 2015, 75, 60-69.

33. Affonso, A.G.; Queiroz, H.L.; De Novo, E.M.L.d.M. Limnological characterization of floodplain lakes in Mamirauá Sustainable Development Reserve, Central Amazon (Amazonas State, Brazil). Acta Limnol. Bras. 2011, 23, 95-108. [CrossRef]

34. Henderson, P.A.; Hamilton, W.D.; Crampton, W.G.R. Evolution and Diversity in Amazonian Floodplain Communities. In Dynamics of Tropical Communities: 37th Symposium of the British Ecological Society; Cambridge University Press: Cambridge, UK, 1998; pp. 384-398.

35. Maccord, P.F.L.; Silvano, R.A.M.; Ramires, M.S.; Clauzet, M.; Begossi, A. Dynamics of artisanal fisheries in two Brazilian Amazonian reserves: Implications to co-management. Hydrobiologia 2007, 583, 365-376. [CrossRef]

36. Castello, L.; Viana, J.P.; Watkins, G.; Pinedo-Vasquez, M.; Luzadis, V.A. Lessons from Integrating Fishers of Arapaima in Small-Scale Fisheries Management at the Mamirauá Reserve, Amazon. Environ. Manag. 2009, 43, 197-209. [CrossRef] [PubMed]

37. Mobley, C.D. Estimation of the Remote-Sensing Reflectance from Above-Surface Measurements. Appl. Opt. 1999, 38, 7442. [CrossRef] [PubMed]

38. Mobley, C.D. Polarized reflectance and transmittance properties of windblown sea surfaces. Appl. Opt. 2015, 54, 4828. [PubMed]

39. Gascon, F.; Cadau, E.; Colin, O.; Hoersch, B.; Isola, C.; López Fernández, B.; Martimort, P. Copernicus Sentinel-2 mission: Products, algorithms and Cal/Val. Proc. SPIE 2014. [CrossRef]

40. Clevers, J.G.P.W.; Gitelson, A.A. Remote estimation of crop and grass chlorophyll and nitrogen content using red-edge bands on Sentinel-2 and -3. Int. J. Appl. Earth Obs. Geoinf. 2013, 23, 344-351. [CrossRef]

41. Baillarin, S.J.; Meygret, A.; Dechoz, C.; Petrucci, B.; Lacherade, S.; Tremas, T.; Isola, C.; Martimort, P.; Spoto, F. Sentinel-2 level 1 products and image processing performances. In Proceedings of the 2012 IEEE International Geoscience and Remote Sensing Symposium, Munich, Germany, 22-27 July 2012; pp. 7003-7006.

42. Kloiber, S.M.; Brezonik, P.L.; Olmanson, L.G.; Bauer, M.E. A procedure for regional lake water clarity assessment using Landsat multispectral data. Remote Sens. Environ. 2002, 82, 38-47.

43. Olmanson, L.G.; Bauer, M.E.; Brezonik, P.L. A 20-year Landsat water clarity census of Minnesota's 10,000 lakes. Remote Sens. Environ. 2008, 112, 4086-4097. [CrossRef]

44. Sriwongsitanon, N.; Surakit, K.; Thianpopirug, S. Influence of atmospheric correction and number of sampling points on the accuracy of water clarity assessment using remote sensing application. J. Hydrol. 2011, 401, 203-220. [CrossRef]

45. Tebbs, E.J.; Remedios, J.J.; Harper, D.M. Remote sensing of chlorophyll-a as a measure of cyanobacterial biomass in Lake Bogoria, a hypertrophic, saline-alkaline, flamingo lake, using Landsat ETM+. Remote Sens. Environ. 2013, 135, 92-106. [CrossRef]

46. Remer, L.A.; Kaufman, Y.J.; Tanré, D.; Mattoo, S.; Chu, D.A.; Martins, J.V.; Li, R.-R.; Ichoku, C.; Levy, R.C.; Kleidman, R.G.; et al. The MODIS Aerosol Algorithm, Products, and Validation. J. Atmos. Sci. 2005, 62, 947-973. [CrossRef] 
47. Gao, B.-C.; Kaufman, Y.J. Water vapor retrievals using Moderate Resolution Imaging Spectroradiometer (MODIS) near-infrared channels. J. Geophys. Res. Atmos. 2003. [CrossRef]

48. Hubanks, P.; Platnick, S.; King, M. MODIS Atmosphere L3 Gridded Product Algorithm Theoretical Basis Document (ATBD); Users Guide, ATBDMOD-30; NASA: Greenbelt, MD, USA, 2015.

49. Jiménez-Muñoz, J.C.; Sobrino, J.A.; Mattar, C.; Franch, B. Atmospheric correction of optical imagery from MODIS and Reanalysis atmospheric products. Remote Sens. Environ. 2010, 114, 2195-2210.

50. Lyapustin, A.; Korkin, S.; Wang, Y.; Quayle, B.; Laszlo, I. Discrimination of biomass burning smoke and clouds in MAIAC algorithm. Atmos. Chem. Phys. 2012, 12, 9679-9686. [CrossRef]

51. Vermote, E.F.; Kotchenova, S. Atmospheric correction for the monitoring of land surfaces. J. Geophys. Res. 2008. [CrossRef]

52. Vermote, E.; Justice, C.; Claverie, M.; Franch, B. Preliminary analysis of the performance of the Landsat 8/OLI land surface reflectance product. Remote Sens. Environ. 2016, 185, 46-56. [CrossRef]

53. Kotchenova, S.Y.; Vermote, E.F.; Matarrese, R.; Klemm, F.J., Jr. Validation of a vector version of the $6 \mathrm{~S}$ radiative transfer code for atmospheric correction of satellite data Part I: Path radiance. Appl. Opt. 2007, 46, 4455-4464. [CrossRef] [PubMed]

54. Vanhellemont, Q.; Ruddick, K. Turbid wakes associated with offshore wind turbines observed with Landsat 8. Remote Sens. Environ. 2014, 145, 105-115. [CrossRef]

55. Vanhellemont, Q.; Ruddick, K. Advantages of high quality SWIR bands for ocean colour processing: Examples from Landsat-8. Remote Sens. Environ. 2015, 161, 89-106. [CrossRef]

56. Pahlevan, N.; Lee, Z.; Wei, J.; Schaaf, C.B.; Schott, J.R.; Berk, A. On-orbit radiometric characterization of OLI (Landsat-8) for applications in aquatic remote sensing. Remote Sens. Environ. 2014, 154, 272-284. [CrossRef]

57. Franz, B.A.; Bailey, S.W.; Kuring, N.; Werdell, P.J. Ocean Color Measurements from Landsat-8 OLI using SeaDAS. In Proceedings of the Ocean Optics XXII, Portland, MA, USA, 26-31 October 2014; pp. 26-31.

58. Uwe, M.-W.; Jerome, L.; Rudolf, R.; Ferran, G.; Marc, N. Sentinel-2 Level 2a Prototype Processor: Architecture, Algorithms and First Results. In Proceedings of the ESA Living Planet Symposium, Edinburgh, UK, 9-13 September 2013.

59. Kaufman, Y.J.; Wald, A.E.; Remer, L.A.; Gao, B.C.; Li, R.-R.; Flynn, L. The MODIS 2.1- $\mu$ m channel-correlation with visible reflectance for use in remote sensing of aerosol. IEEE Trans. Geosci. Remote Sens. 1997, 35, 1286-1298. [CrossRef]

60. Tanre, D.; Herman, M.; Deschamps, P.Y. Influence of the background contribution upon space measurements of ground reflectance. Appl. Opt. 1981, 20, 3676-3684. [CrossRef] [PubMed]

61. Otterman, J.; Fraser, R.S. Adjacency effects on imaging by surface reflection and atmospheric scattering: cross radiance to zenith. Appl. Opt. 1979, 18, 2852-2860. [CrossRef] [PubMed]

62. Kaufman, Y.J. Atmospheric effect on spatial resolution of surface imagery. Appl. Opt. 1984, 23, 4164-4172. [PubMed]

63. Chervet, P.; Lavigne, C.; Roblin, A.; Bruscaglioni, P. Effects of aerosol scattering phase function formulation on point-spread-function calculations. Appl. Opt. 2002, 41, 6489-6498. [CrossRef] [PubMed]

64. Minomura, M.; Kuze, H.; Takeuchi, N. Adjacency effect in the atmospheric correction of satellite remote sensing data: evaluation of the influence of aerosol extinction profiles. Opt. Rev. 2001, 8, 133-141. [CrossRef]

65. Dor, B.B.; Devir, A.D.; Shaviv, G.; Bruscaglioni, P.; Donelli, P.; Ismaelli, A. Atmospheric scattering effect on spatial resolution of imaging systems. Opt. Soc. Am. 1997, 14, 1329-1337.

66. Huang, C.; Townshend, J.R.G.; Liang, S.; Kalluri, S.N.V.; Defries, R.S. Impact of sensor's point spread function on land cover characterization: assessment and deconvolution. Remote Sens. Environ. 2002, 80, $203-212$. [CrossRef]

67. Radoux, J.; Chomé, G.; Jacques, D.C.; Waldner, F.; Bellemans, N.; Matton, N.; Lamarche, C.; D'Andrimont, R.; Defourny, P. Sentinel-2's Potential for Sub-Pixel Landscape Feature Detection. Remote Sens. 2016, 8, 488. [CrossRef]

68. Sei, A. Efficient correction of adjacency effects for high- resolution imagery: Integral equations, analytic continuation, and Padé approximants. Appl. Opt. 2015, 54, 3748-3758. [CrossRef]

69. Duan, S.B.; Li, Z.L.; Tang, B.-H.; Wu, H.; Tang, R.; Bi, Y. Atmospheric correction of high-spatial-resolution satellite images with adjacency effects: Application to EO-1 ALI data. Int. J. Remote Sens. 2015, 36, 5061-5074. [CrossRef] 
70. Vermote, E.F.; El Saleous, N.; Justice, C.O.; Kaufman, Y.J.; Privette, J.L.; Remer, L.; Roger, J.C.; Tanré, D. Atmospheric correction of visible to middle-infrared EOS-MODIS data over land surfaces: Background, operational algorithm and validation. J. Geophys. Res. 1997, 102, 17131-17141. [CrossRef]

71. Burazerovic, D.; Geens, B.; Heylen, R.; Sterckx, S.; Scheunders, P. Unmixing for detection and quantification of adjacency effects. In Proceedings of the 2012 IEEE International Geoscience and Remote Sensing Symposium, Munich, Germany, 22-27 July 2012; pp. 3090-3093.

72. Keshava, N.; Mustard, J.F. Spectral unmixing. IEEE Signal Process. Mag. 2002, 19, 44-57. [CrossRef]

73. Seidel, F.C.; Popp, C. Critical surface albedo and its implications to aerosol remote sensing. Atmos. Meas. Tech. 2012, 5, 1653-1665. [CrossRef]

74. Remer, L.A.; Tanre, D.; Kaufman, Y.J.; Levy, R.; Mattoo, S. Algorithm for Remote Sensing of Tropospheric Aerosol from MODIS: Collection 005; NASA: Merritt Island, FL, USA, 2006.

75. Kondratyev, K.Y.; Kozoderov, V.V.; Smokty, O.I. Remote Sensing of the Earth from Space: Atmospheric Correction; Springer: Berlin, Germany, 2013.

76. Hilker, T.; Lyapustin, A.I.; Hall, F.G.; Myneni, R.; Knyazikhin, Y.; Wang, Y.; Tucker, C.J.; Sellers, P.J. On the measurability of change in Amazon vegetation from MODIS. Remote Sens. Environ. 2015, 166, 233-242.

77. Videla, F.C.; Barnaba, F.; Angelini, F.; Cremades, P.; Gobbi, G.P. The relative role of amazonian and non-amazonian fires in building up the aerosol optical depth in South America: A five year study (2005-2009). Atmos. Res. 2013, 122, 298-309. [CrossRef]

78. Artaxo, P.; Rizzo, L.V.; Brito, J.F.; Barbosa, H.M.J.; Arana, A.; Sena, E.T.; Cirino, G.G.; Bastos, W.; Martin, S.T.; Andreae, M.O. Atmospheric aerosols in Amazonia and land use change: From natural biogenic to biomass burning conditions. Faraday Discuss. 2013, 165, 203-235. [CrossRef] [PubMed]

79. Bodhaine, B.A.; Wood, N.B.; Dutton, E.G.; Slusser, J.R. On Rayleigh optical depth calculations. J. Atmos. Ocean. Technol. 1999, 16, 1854-1861. [CrossRef]

80. Kutser, T.; Pierson, D.C.; Kallio, K.Y.; Reinart, A.; Sobek, S. Mapping lake CDOM by satellite remote sensing. Remote Sens. Environ. 2005, 94, 535-540. [CrossRef]

81. Matthews, M.W. A current review of empirical procedures of remote sensing in inland and near-coastal transitional waters. Int. J. Remote Sens. 2011, 32, 6855-6899. [CrossRef]

82. Odermatt, D.; Gitelson, A.; Brando, V.E.; Schaepman, M. Review of constituent retrieval in optically deep and complex waters from satellite imagery. Remote Sens. Environ. 2012, 118, 116-126. [CrossRef]

83. Bassani, C.; Manzo, C.; Braga, F.; Bresciani, M.; Giardino, C.; Alberotanza, L. The impact of the microphysical properties of aerosol on the atmospheric correction of hyperspectral data in coastal waters. Atmos. Meas. Tech. 2015, 8, 1593-1604. [CrossRef]

84. Li, Z.; Zhao, X.; Kahn, R.; Mishchenko, M.; Remer, L.; Lee, K.-H.; Wang, M.; Laszlo, I.; Nakajima, T.; Maring, H. Uncertainties in satellite remote sensing of aerosols and impact on monitoring its long-term trend: A review and perspective. Ann. Geophys. 2009, 27, 2755-2770. [CrossRef]

85. Eck, T.F.; Holben, B.N.; Reid, J.S.; Dubovik, O.; Smirnov, A.; O’Neill, N.T.; Slutsker, I.; Kinne, S. Wavelength dependence of the optical depth of biomass burning, urban, and desert dust aerosols. J. Geophys. Res. 1999, 104, 31333-31349.

86. Barnes, B.B.; Hu, C.; Kovach, C.; Silverstein, R.N. Sediment plumes induced by the Port of Miami dredging: Analysis and interpretation using Landsat and MODIS data. Remote Sens. Environ. 2015, 170, 328-339. [CrossRef]

87. Garaba, S.P.; Zielinski, O. An assessment of water quality monitoring tools in an estuarine system. Remote Sens. Appl. Soc. Environ. 2015, 2, 1-10. [CrossRef]

88. Louis, J.; Debaecker, V.; Pflug, B.; Main-Knorn, M. Sentinel-2 Sen2Cor: L2A Processor for Users. In Proceedings of the Living Planet Symposium, Prague, Czech Republic, 9-13 May 2016.

89. Wilson, R.T. Py6S: A Python interface to the 6S radiative transfer model. Comput. Geosci. 2013, 51, $166-171$. [CrossRef]

(C) 2017 by the authors. Licensee MDPI, Basel, Switzerland. This article is an open access article distributed under the terms and conditions of the Creative Commons Attribution (CC BY) license (http:/ / creativecommons.org/licenses/by/4.0/). 